\title{
Statistical analysis of the hydrodynamic forces
}

\section{acting on pipe bends in gas-liquid slug flow and}

\section{their relation to fatigue}

\author{
Boon Li Tay ${ }^{a, *}$, Rex B. Thorpe ${ }^{b}$ \\ ${ }^{a}$ Department of Chemical Engineering, \\ University of Cambridge, \\ Pembroke Street, Cambridge CB2 3RA, UK. \\ ${ }^{\mathrm{b}}$ Department of Chemical and Process Engineering, \\ University of Surrey, \\ Guildford GU2 7XH, UK.
}

\begin{abstract}
In this paper, the resultant hydrodynamic force $\left(F_{R}\right.$, where $\left.F_{R}=\sqrt{F_{x}{ }^{2}+F_{y}{ }^{2}}\right)$ acting on pipe bends will be discussed. A hypothesis that the peak (resultant) forces, $F_{R \text {, peak }}$ acting on pipe bends can be described by the normal distribution function will be tested, with the purpose of predicting the mean of the $F_{R \text {, peak }}\left(F_{R \text {, mean }}\right)$ and the standard deviations of the $F_{R, \text { peak }}\left(F_{R, \text { standard deviation }}\right)$ generated. This in turn allows prediction of the probability of the largest forces that occasionally occur at various flow rates. This information is vital in designing an appropriate support for the piping system, to cater the maximum force over a long period of operation. Besides, this information is also important in selecting a pipe material or material for connections suitable to withstand fatigue failure, by reference to the $S$ - $N$ curves of materials. In many cases, large numbers of response cycles may accumulate over the life of the structure. By knowing the force distribution, 'cumulative damage' can also be determined; 'cumulative damage' is another phenomenon that can cause fatigue, apart from the reversal maximum force.
\end{abstract}

Key Words: slug flow, bend, force, statistical analysis, fatigue, cumulative damage. * Corresponding author (email: boonli.tay@outlook.com) 


\section{Introduction}

Slug flow is difficult to model in that slugs have varying lengths, densities, and configurations; the forces acting on pipe bends or other pipe fittings vary with the slugs. Distribution analysis of the resultant forces acting on pipe bends, due to the hydrodynamic behaviour of slug flow, may be applied to serviceability checks and fatigue cycle counting. This provides guidance to the designer whether or not the dynamics are of importance i.e. not safely covered by fatigue load factors in conventional checks. A brief summary of metal fatigue is attached in the Appendix.

Santana et al. (1993) reported that two-phase slug flow has been evident in the piping systems at ARCO's Kuparuk River Unit, North Slope, Alaska since shortly after startup in 1981. They further reported that the forces associated with slug flow had caused excessive movement of partially restrained piping. Unrestrained elbows, tees and vessel nozzles and internals were subject to deformation and cyclic stress. Eventually, the magnitude and number of stress reversals caused fatigue cracking in piping branch connections and a pressure vessel nozzle. They mentioned that research had been carried out on the impacts of slug flow on their operating facilities. ARCO installed a data acquisition system that records historic information such as the frequency of slugs and accompanying stress reversals for a time period of a year or more, to provide an accurate indication of the number and magnitude of stress reversal cycles experienced by piping, vessel, and support structures. This will have allowed fatigue usage of the components of ARCO's modified design to be estimated, and it will also have been useful in predicting the remaining fatigue life of the components. However, Santana et al. give no detail of the data acquired. 
The linear cumulative damage rule as defined by Miner (1945) is used in the majority of fatigue life calculations. This rule assumes that if a bend has received $n_{1}$ cycles at stress ${ }_{1}$ for which the expected number of cycles to failure is $N_{1}$ then a fraction $n_{1} / N_{1}$ of the useful life is used up (Alexander \& Brewer, 1963). The 'cumulative damage' is calculated as:

$$
\frac{n_{1}}{N_{1}}+\frac{n_{2}}{N_{2}}+\cdots=\sum_{i=1}^{i} \frac{n_{i}}{N_{i}}
$$

Failure will occur when $\sum_{i=1}^{i} \frac{n_{i}}{N_{i}}=1$. A design value less than unity is generally used. Cook and Claydon (1992) reported that tests have shown significant scatter and a marked load order dependency and values of cumulative damage between 0.3 and 3 have been obtained. Despite this load order dependency, there has been no physical basis supporting the assumptions behind Miner (1945)'s rule; although this has widespread usage in service life prediction in early stages of design. Cook \& Claydon (1992) further mentioned that in order to account for such a large scatter in fatigue test data and variability in critical damage constant defined above, a factor of $1 / 5$ th or less is typically used in design life calculations.

In addition, investigation showed the fatigue strength of un-welded pipe is twice of the welded pipes, as a result of high stress concentration on the notch at the weld root (Gurney, 1968). At a pipe bend there are higher stresses than exist in adjoining straight runs of pipe (Gurney, 1968). Under an applied bending moment the cross-section of the pipe tends to become oval, as shown in Figure 1. The fatigue strength of a bend will be a function, by a factor less than unity, of the fatigue strength of the material. 

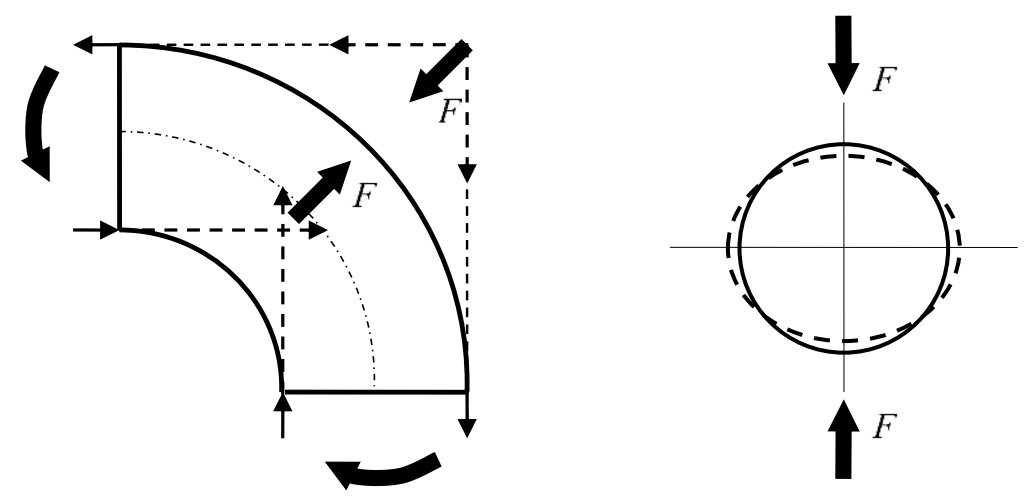

Figure 1 The effect of applying a bending moment to a pipe bend is to cause ovalling of the pipe with consequent high transverse bending stresses at the 'neutral axis'.

The usefulness of the research is not confined to conventional bends. In oil and gas production systems, typical seabed connections are divided into four generic groups: elastomeric flex, mechanical hose, flexible hose and metal flex joints. Nevertheless, all these joints are exposed to the risk of fatigue failure (Goodfellow Associates, 1986). Most of the components are made of steel. In certain circumstances titanium with better fatigue performance than steel, as shown in Figure A.1, may be used for metal flex joints to provide a cost-effective solution (Goodfellow Associates, 1986).

Established studies have been done on the fatigue characteristic of various metals in many shapes and different operating and aging conditions. Numerical information is readily available (Gatts, 1961; Gurney, 1968; Hilsenkopf, 1988; Kitching, 1979; Klesnil \& Lunáš, 1992; Pope, 1959; Shalaby \& Younan, 1999 \& 1998 and Tottle, 1984). 


\section{Experiment set-up}

Force on pipe bends due to slug flow is an unsteady-state phenomenon. Therefore, it is pertinent to obtain time varying measurements of the impact and some slug characteristics, including slug velocity, liquid hold-up and pressure at the inlet and outlet of the bend that contribute to this impact. It has been shown that isolating the bend from the upstream and downstream pipe works is vital (Tay and Thorpe, 2002, 2004, 2014; Fairhurst, 1983; Hargreaves and Slocombe, 1998). The experimental data discussed in this paper was collected from the same experimental rig used by Tay \& Thorpe $(2002,2004,2014)$. A short description of the experimental setup is given below.

The experimental rig was set up where air and water were mixed via a T-mixer and fed to the flow system. The flow then ran through a $9 \mathrm{~m}$ horizontal run, where slug flow is developed (naturally downstream of the T-mixer at certain gas and liquid velocities), followed by a bend set-up (Figure 2) and a $3.0 \mathrm{~m}$ horizontal pipe, and finally discharged at atmospheric pressure into an opened-top slug catcher. Water collected in the slug catcher was returned to a water tank and re-circulated.

A $90^{\circ}$ stainless steel bend of radius $105 \mathrm{~mm}$ and an internal diameter of $70 \mathrm{~mm}$, which gives a bend radius to pipe diameter ratio of $R / D=1.5$, was setup as shown in Figure 2 . Gaps of $3 \mathrm{~mm}$ were allowed between the bend and upstream and downstream pipe works, to minimize structural transmission to and from the pipe bend, where force measurements were taken. The gaps were closed from the external pipe wall using two sets of bellows, see Figure 3. This setup reduced the disturbance on the main stream due to the sudden increase and decrease in the flow area and eliminated the disturbance on the mainstream due to the corrugated surface of the bellows (Tay and Thorpe, 2014). 


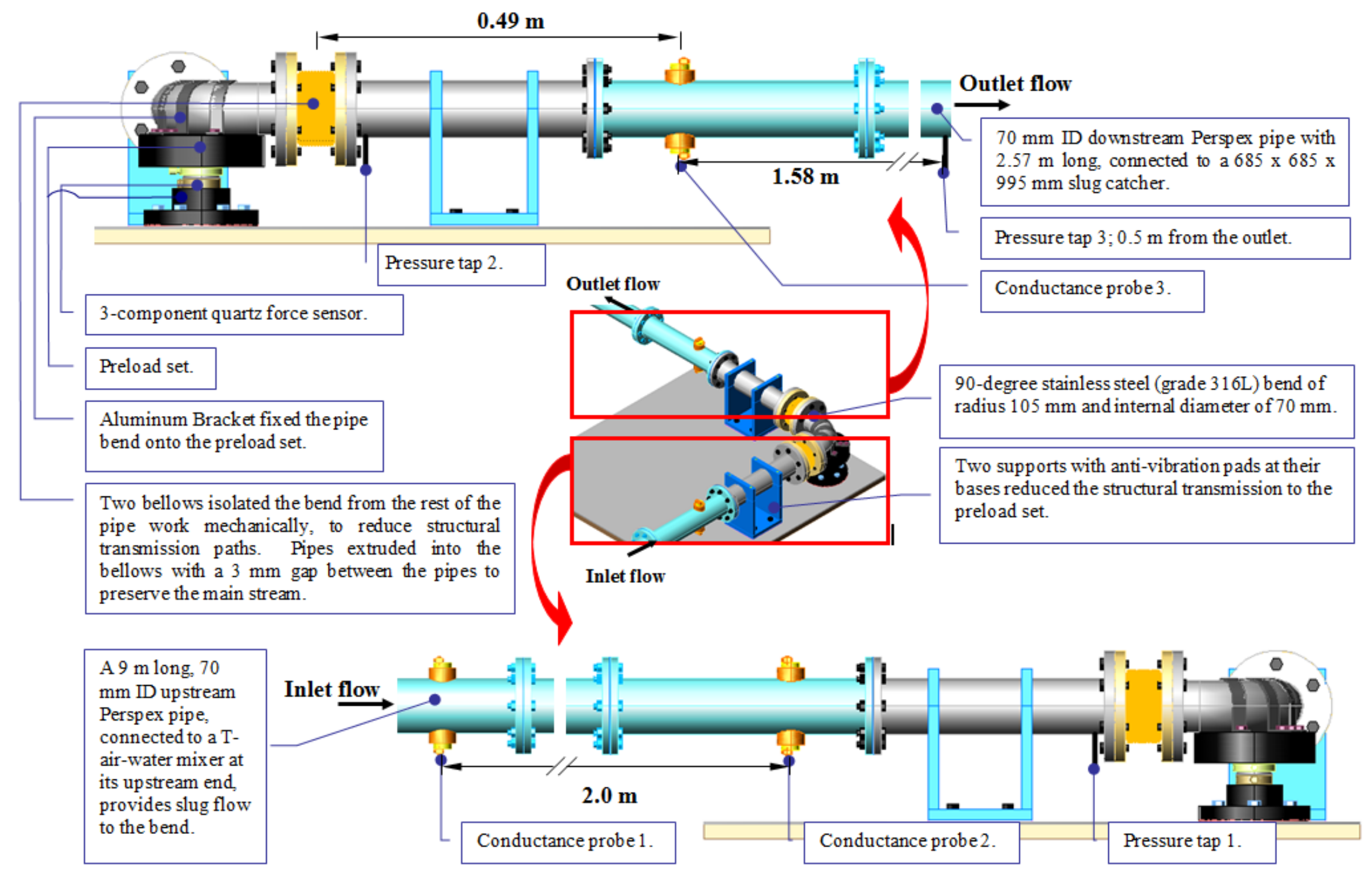

Figure 2 Bend set-up. 


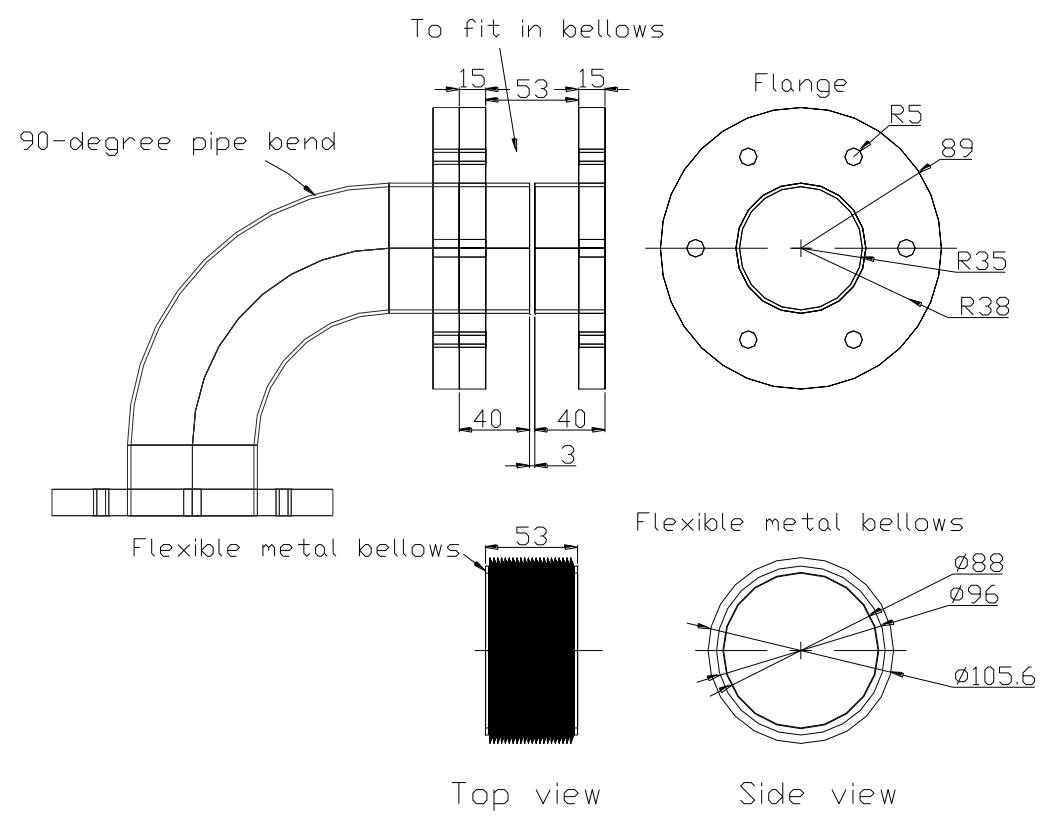

Figure 3 Bend connections in the current study.

The bend was fixed onto the preload set with a quartz force sensor (Kistler, 9167A1.5) clamped in between. This sensor contains quartz rings that are sensitive to shear and so measures the force components $F_{x}$ and $F_{y}$. Continuous measurement of $x$ - and $y-$ component forces is possible to give time-dependent force traces with an effectively instantaneous response time; the data points were recorded every $10 \mathrm{~ms}$.

Tay and Thorpe $(2002,2004,2014)$ set up their experimental rig based on their defined control volume analysis of a horizontal pipe bend as shown in Figure 4. Following this, the control surfaces of analysis were placed through the $3 \mathrm{~mm}$ gaps in the bellows to eliminate the force in the pipe metal $\left(\underline{\boldsymbol{F}}_{\text {stress }}\right)$. Ideally, pressure at these locations should be measured in order to be able to calculate the pressure-area terms as proposed by Tay and Thorpe $(2002,2004,2014)$ in their Piston Flow Model (PFM): 


$$
F_{x}=\rho_{A} A j_{s} u_{s}+\left(P_{i, a^{\prime}} A-P_{o} A\right)-\underbrace{\left(\begin{array}{l}
{\left[\rho_{A} A j_{s} \frac{\partial}{\partial t}\left(l-l_{a^{\prime}}\right)+\rho_{B} A j_{s} \frac{\partial}{\partial t}\left(l_{b^{\prime}}-l\right)\right]+} \\
{\left[\rho_{A} A j_{s} R \frac{\partial}{\partial t} \sin \left(\omega\left(t-t_{b^{\prime}}\right)\right)-\rho_{B} A j_{s} R \frac{\partial}{\partial t} \sin \left(\omega\left(t-t_{b^{\prime}}\right)\right)\right]}
\end{array}\right)}_{\text {rate of changeof momentum }}
$$

$$
F_{y}=\rho_{B} A j_{s} u_{s}+\left(P_{i, e^{\prime}} A-P_{o} A\right)+\underbrace{\left(\begin{array}{l}
{\left[-\rho_{A} A j_{s} R \frac{\partial}{\partial t} \cos \left(\omega\left(t-t_{b^{\prime}}\right)\right)+\rho_{B} A j_{s} R \frac{\partial}{\partial t} \cos \left(\omega\left(t-t_{b^{\prime}}\right)\right)\right]+} \\
{\left[\rho_{A} A j_{s} \frac{\partial}{\partial t}\left(l-l_{d^{\prime}}\right)+\rho_{B} A j_{s} \frac{\partial}{\partial t}\left(l_{e^{\prime}}-l\right)\right]}
\end{array}\right)}_{\text {rate of changeof momentum }}
$$

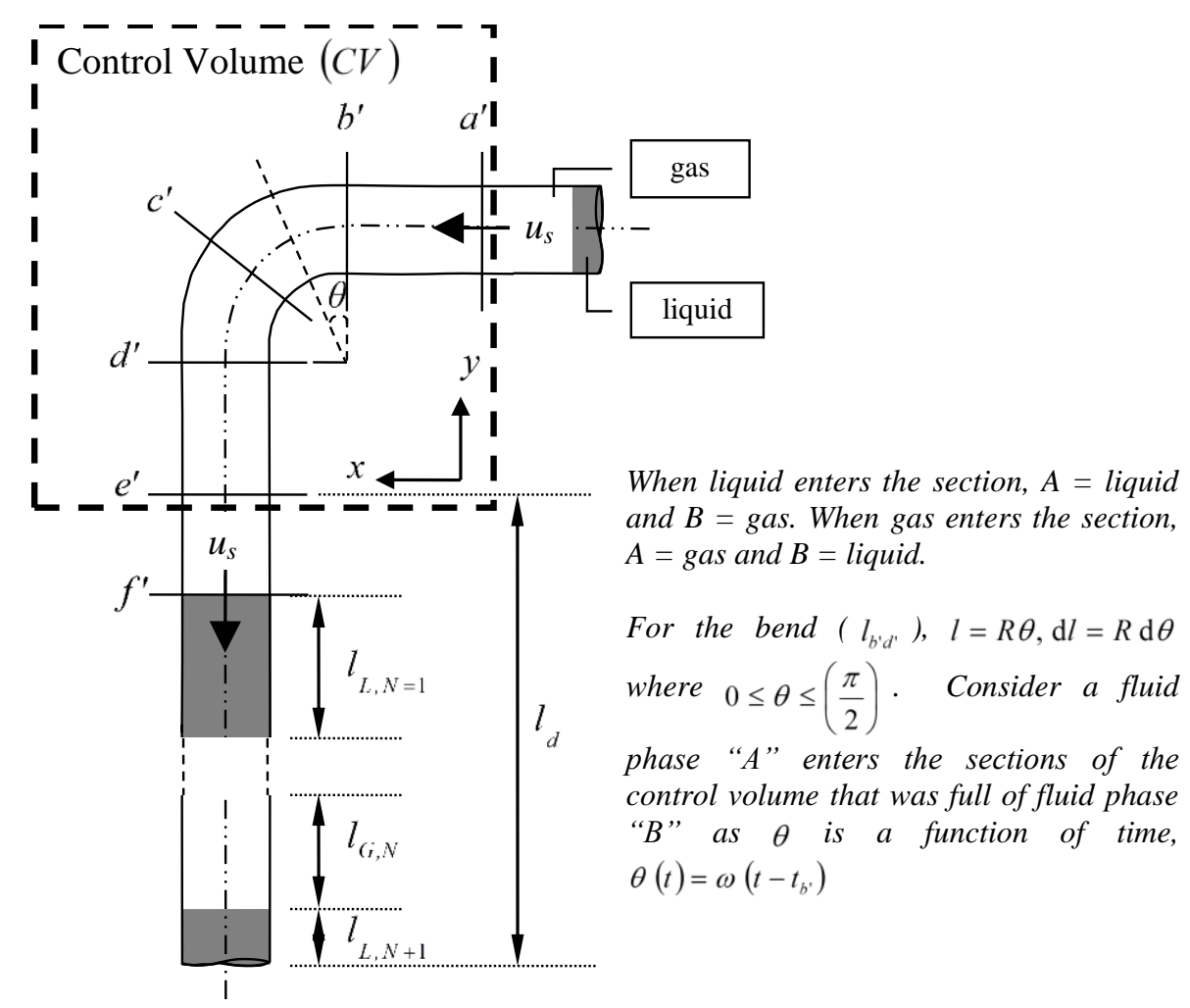

Outlet of the flow

Figure 4 Pipe bend flow in horizontal plane with a defined control volume of analysis.

However, it is difficult to install pressure transducers on/through the bellows. Therefore the pressure transducers were placed at a distance $55 \mathrm{~mm}$ from the $3 \mathrm{~mm}$ gaps (see Figure 2) before and after the bend, respectively. The pressure profiles measured at these 
locations, after correction with a lag-time have been taken as the pressure profiles at the 3 mm gaps. Another pressure transducer was placed $1.5 \mathrm{~m}$ downstream after the bend.

Three conductance probes were located along the flow line, to provide information on slug velocity, liquid hold-up and slug lengths. The conductance probes are made of two parallel $0.125 \mathrm{~mm}$ stainless steel AISI 316L wires (Advent Research Materials Ltd, FE632818) spaced $2 \mathrm{~mm}$ apart, passing vertically from the top to the bottom of the pipe. Linear calibration relations were obtained between water level and output voltage. Tay and Thorpe (2014) discussed the detailed setup of these conductance probes. The first two probes were located $2.5 \mathrm{~m}$ (conductance probe 1) and $0.5 \mathrm{~m}$ (conductance probe 2 ) before the bend, providing information on the slugs entering the bend. The other conductance probe was placed $0.5 \mathrm{~m}$ after the bend, providing information on slugs leaving the bend. Slug velocity $\left(u_{s}\right)$ was obtained by dividing the distance between two conductance probes, by the time taken for the liquid slug front to travel through these two points. Liquid heights at these locations rose when a liquid slug front arrived as shown in Figure 6. Liquid hold-up was calculated as:

$$
H_{L}=\frac{A_{L}}{A}
$$

where

$$
\begin{aligned}
& A_{L}=\frac{1}{8}[(2 \alpha)-\sin (2 \alpha)] D^{2} \\
& \alpha=\sin ^{-1}\left[\frac{2}{D} \sqrt{h(D-h)}\right]
\end{aligned}
$$

$\alpha$ and $h$ are shown in Figure 5. 


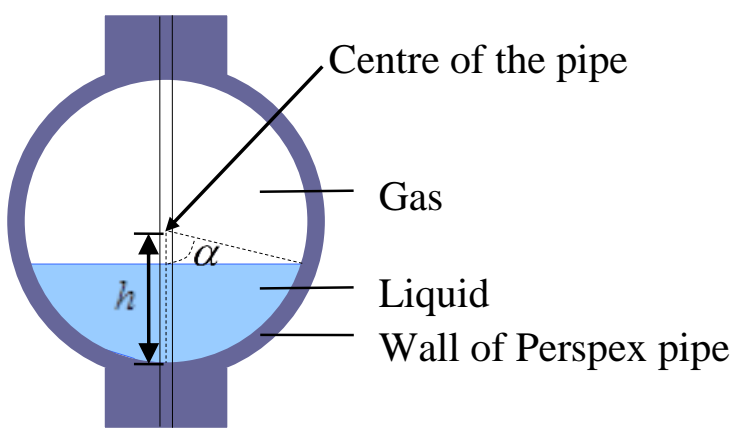

Figure 5 Cross sectional view of pipe.

All the measuring devices were connected to a PC where the data were recorded using a data acquisition program.

\section{Experimental results: Statistical analysis of forces on pipe bend}

\subsection{Experimental force traces}

A typical resultant force trace is given in Figure 6 . The peak (resultant) force, $F_{R \text {, peak }}$, is the largest (resultant) force in the time-dependent resultant force trace imposed on the pipe bend during transit of a slug unit. The maximum force, $F_{R, \max }$, is therefore referred to the largest among the $F_{R, \text { peak }}$ s over a test period. In Figure $6, F_{R, \text { peakslug } 3}$ is the $F_{R, \max }$ over the $16 \mathrm{~s}$ measurement. 


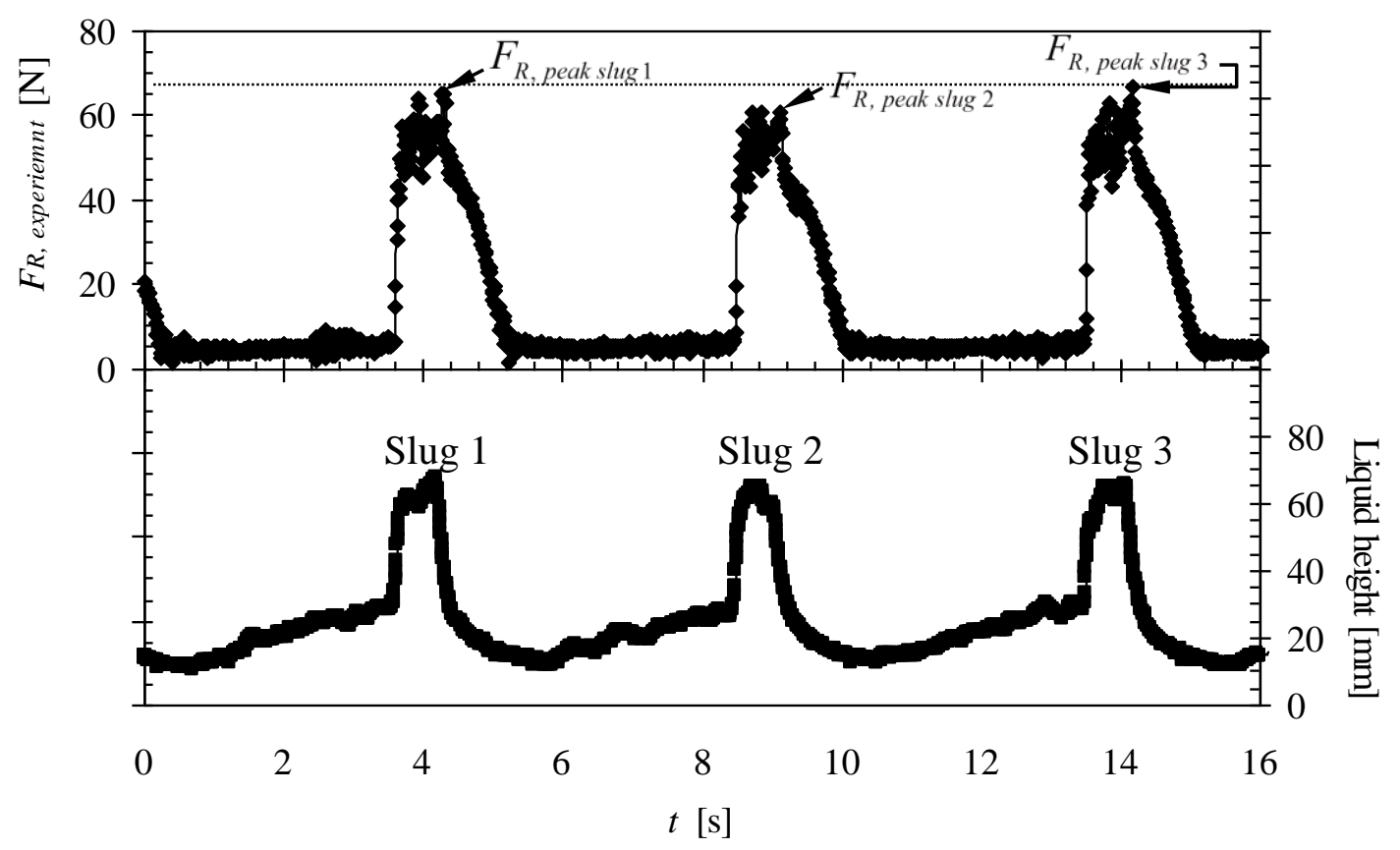

Figure 6 Traces of resultant force $(\rightarrow)$ with liquid level $(\rightarrow)$-in the pipe. (

$$
\left.j_{L}=0.5 \mathrm{~m} . \mathrm{s}^{-1} ; j_{G}=1.8 \mathrm{~m} \cdot \mathrm{s}^{-1}\right)
$$

\subsection{6-minute tests}

Figure 7 to Figure 16 show a series of histogram plots, for the magnitudes of $F_{R \text {, peak }}$ acting on the bend in 6 minutes, obtained for $j_{L}=0.6 \mathrm{~m} \cdot \mathrm{s}^{-1}$ and $0.38 \mathrm{~m} . \mathrm{s}^{-1} \leq j_{G} \leq 2.87 \mathrm{~m} . \mathrm{s}^{-1}$ . To obtain the above plots, magnitudes of the $F_{R \text {, peak }}$ acting on the bend were distributed into classes having the same size, for the range of magnitude measured $(0-150 \mathrm{~N})$ i.e. $F_{R, \text { peak } i}$ where $i=1,2, \ldots, 150$. The magnitudes of $F_{R \text {, peak }}$ were then distributed into the corresponding classes. This allows the corresponding class frequencies i.e. number of slugs for each force class to be determined as shown in Figure 7 to Figure 16. Similar plots were obtained for other flow rates used in the current study; where $0.2 \mathrm{~m} . \mathrm{s}^{-1} \leq j_{L} \leq 0.7 \mathrm{~m} . \mathrm{s}^{-1}$ and $0.38 \mathrm{~m} \cdot \mathrm{s}^{-1} \leq j_{G} \leq 2.87 \mathrm{~m} \cdot \mathrm{s}^{-1}$. 


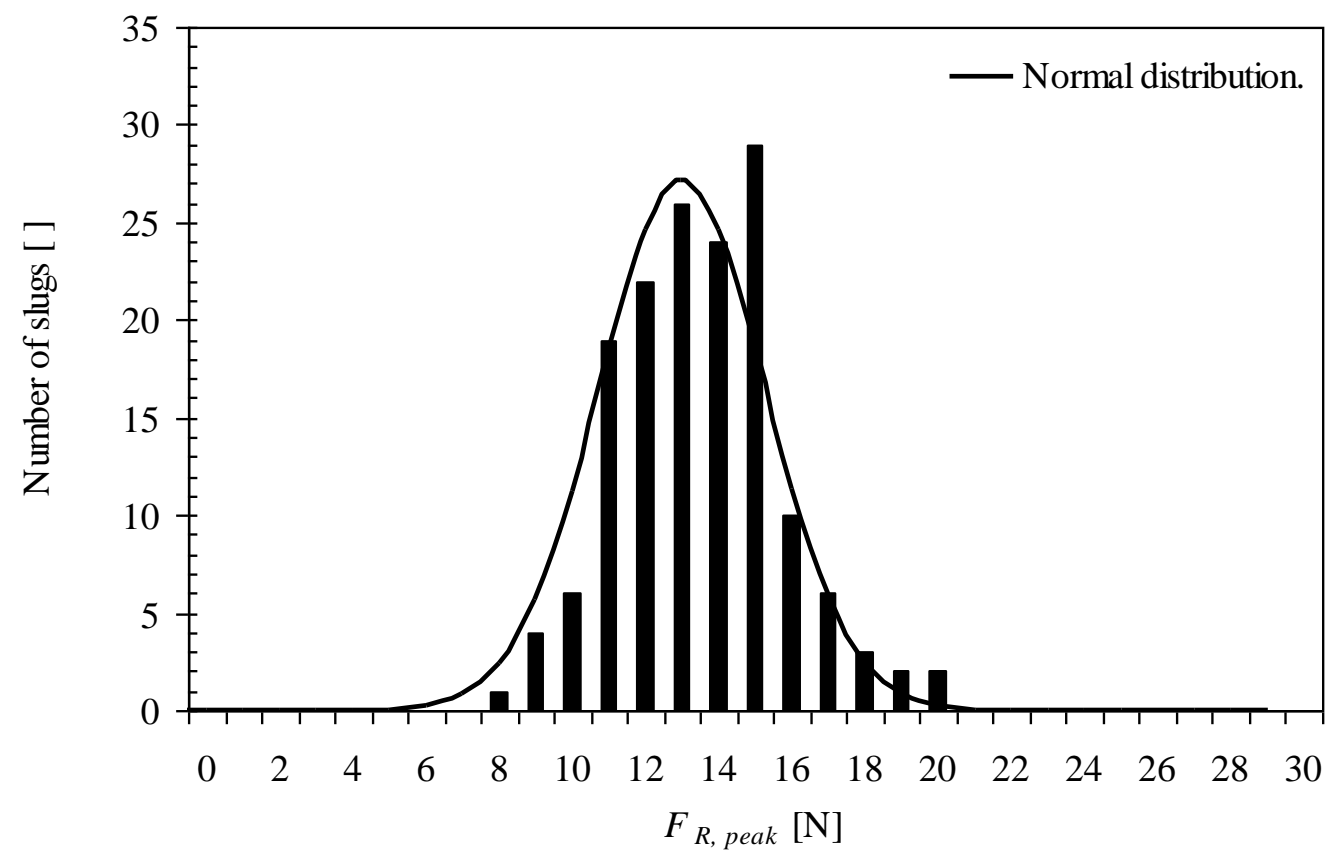

Figure 7 Frequencies of the $F_{R, \text { peak }} \mathrm{s}$ acting on a pipe bend in slug flow, in 6 minutes;

$$
j_{L}=0.6 \mathrm{~m} \cdot \mathrm{s}^{-1}, j_{G}=0.38 \mathrm{~m} \cdot \mathrm{s}^{-1}
$$

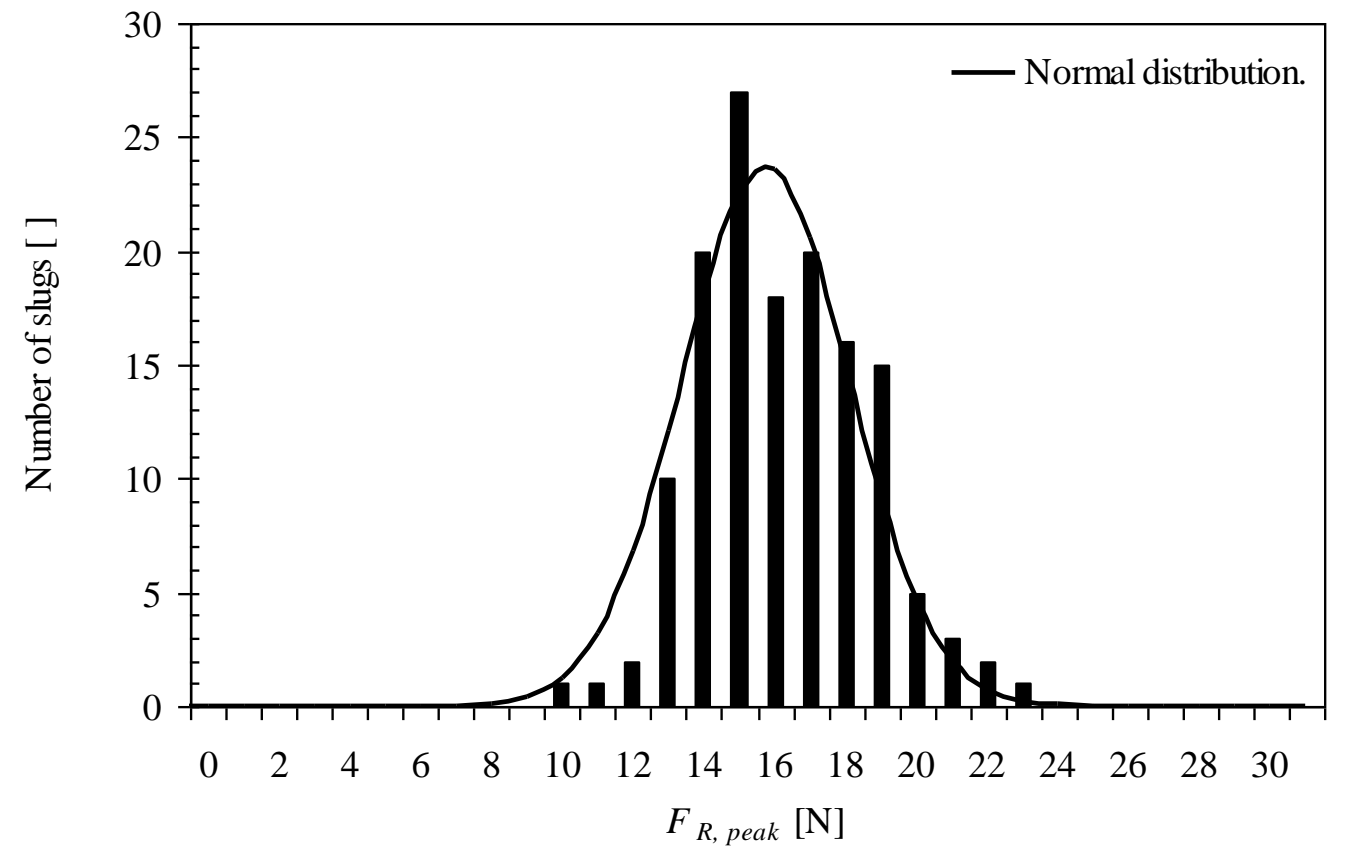

Figure 8 Frequencies of the $F_{R, \text { peak }} \mathrm{s}$ acting on a pipe bend in slug flow, in 6 minutes;

$$
j_{L}=0.6 \mathrm{~m} \cdot \mathrm{s}^{-1}, j_{G}=0.60 \mathrm{~m} \cdot \mathrm{s}^{-1}
$$




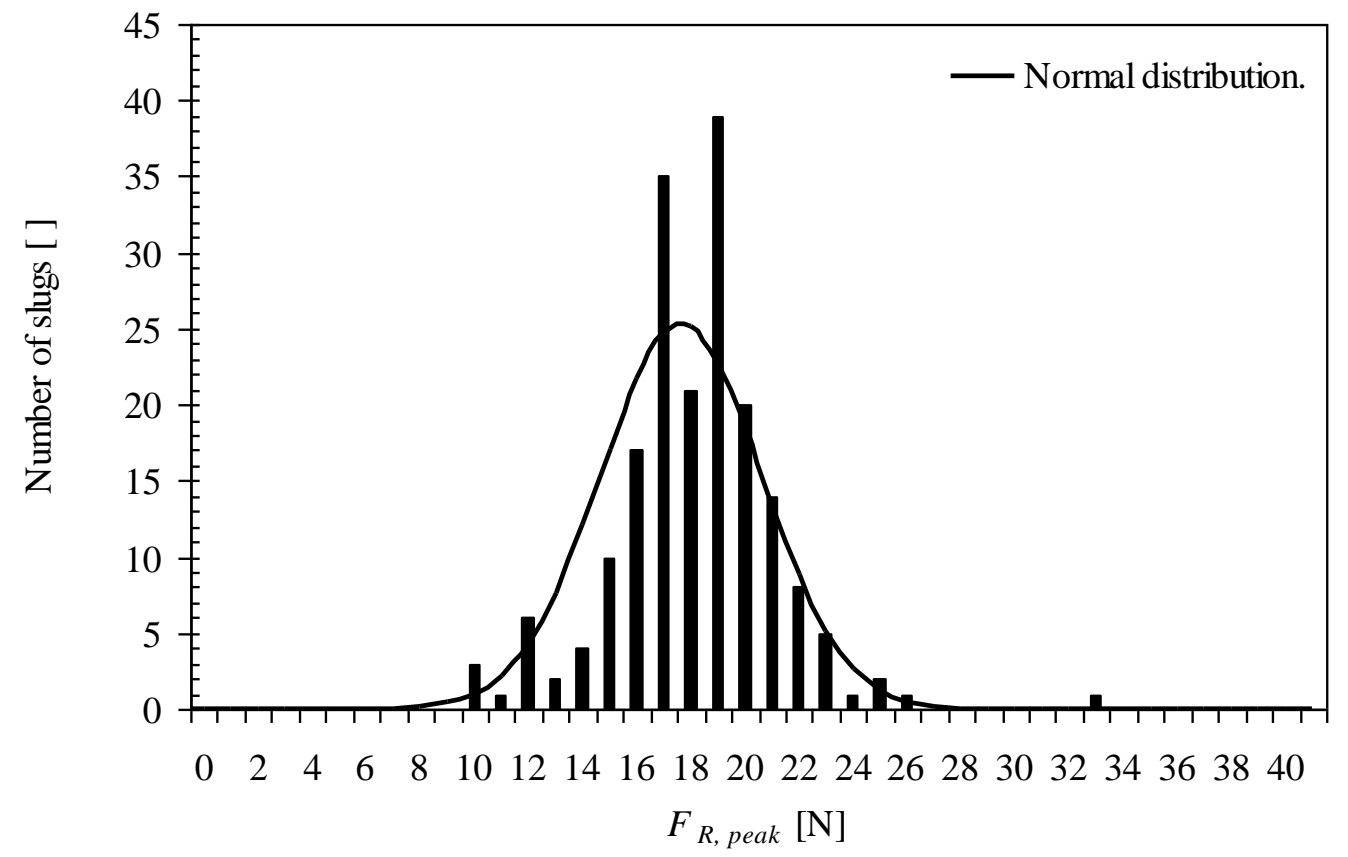

Figure 9 Frequencies of the $F_{R, \text { peak }} \mathrm{s}$ acting on a pipe bend in slug flow, in 6 minutes;

$$
j_{L}=0.6 \mathrm{~m} \cdot \mathrm{s}^{-1}, j_{G}=0.83 \mathrm{~m} \cdot \mathrm{s}^{-1}
$$

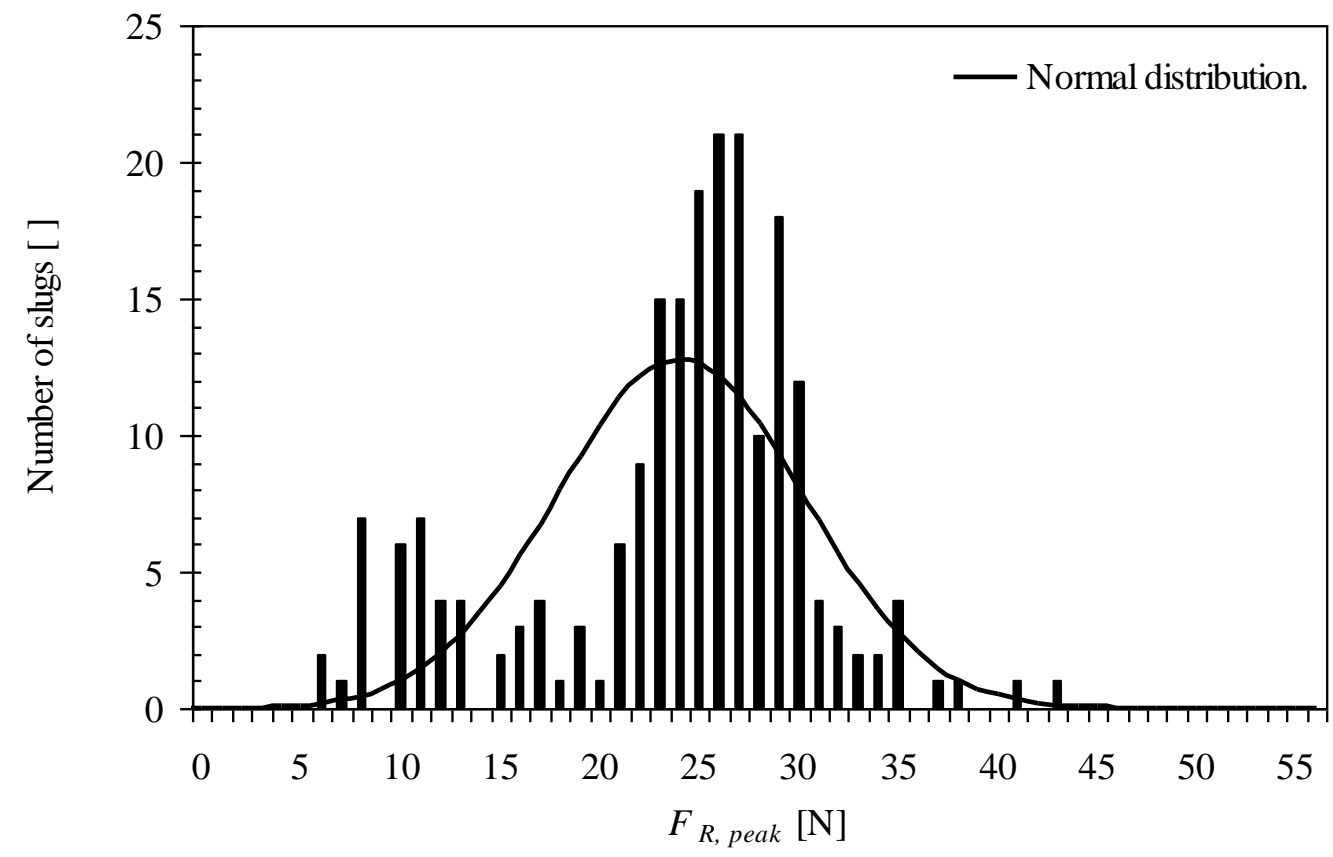

Figure 10 Frequencies of the $F_{R \text {, peak }} \mathrm{s}$ acting on a pipe bend in slug flow, in 6 minutes;

$$
j_{L}=0.6 \mathrm{~m} \cdot \mathrm{s}^{-1}, j_{G}=1.28 \mathrm{~m} \cdot \mathrm{s}^{-1} .
$$




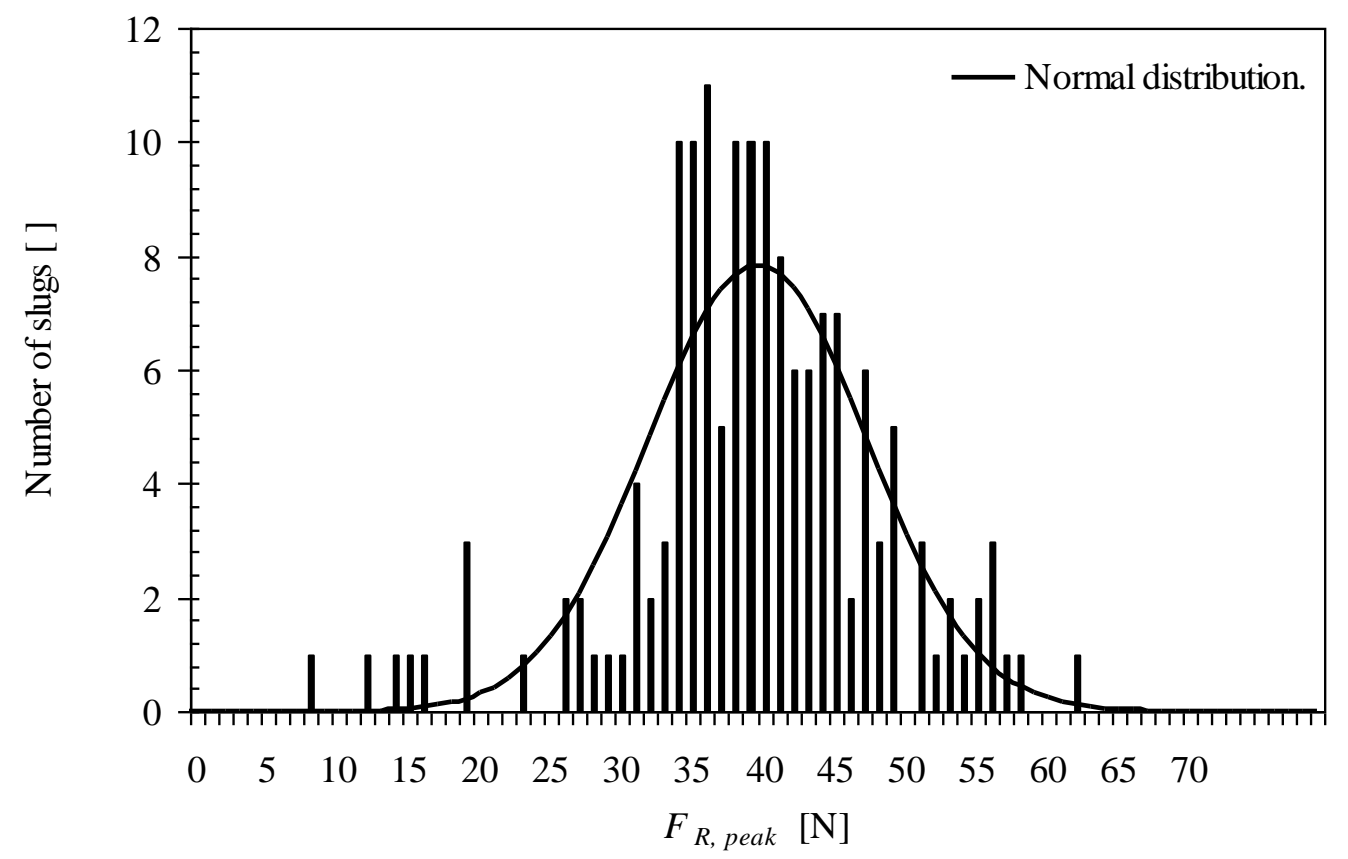

Figure 11 Frequencies of the $F_{R \text {, peak }} \mathrm{s}$ acting on a pipe bend in slug flow, in 6 minutes;

$$
j_{L}=0.6 \mathrm{~m} . \mathrm{s}^{-1}, j_{G}=1.72 \mathrm{~m} \cdot \mathrm{s}^{-1} .
$$

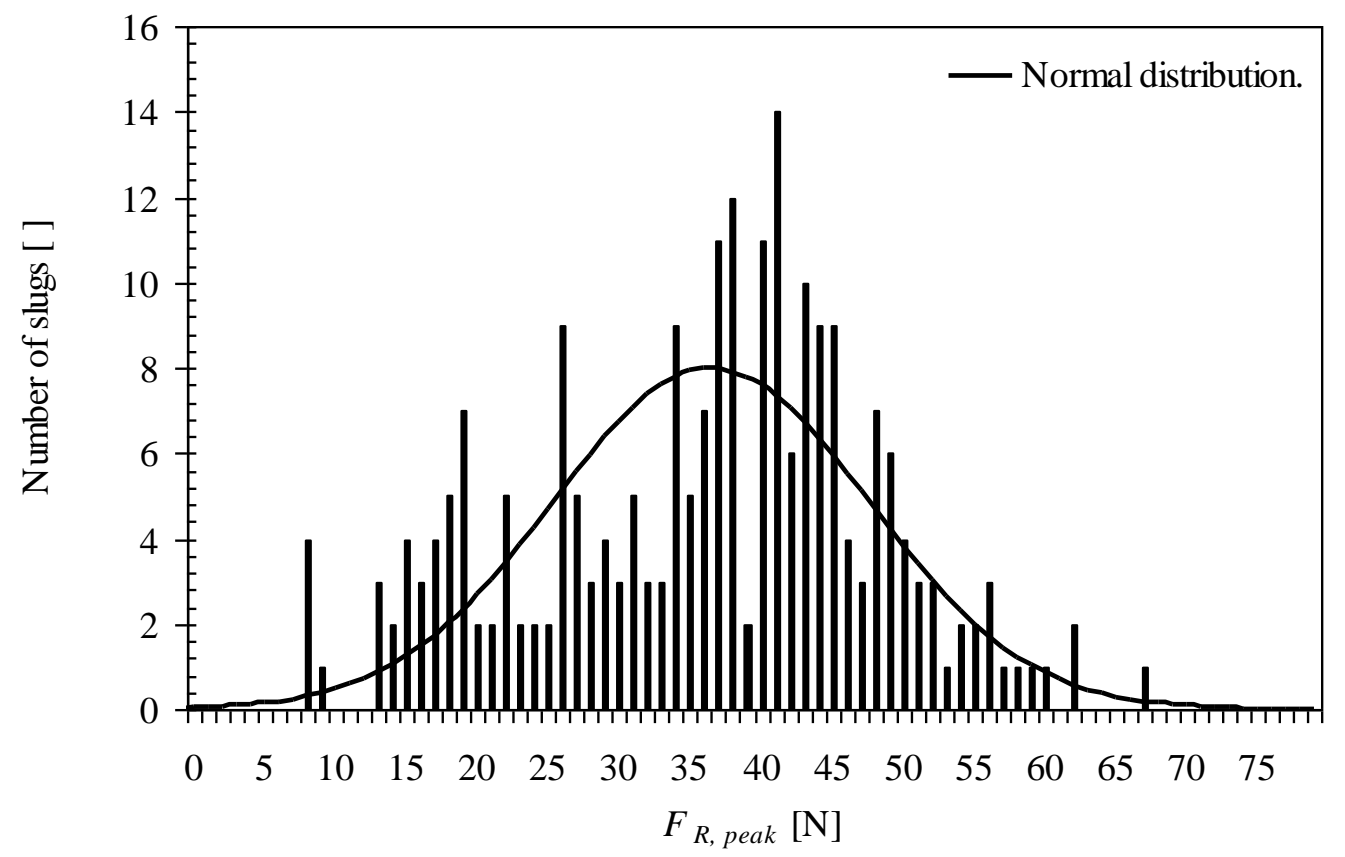

Figure 12 Frequencies of the $F_{R, p e a k} \mathrm{~s}$ acting on a pipe bend in slug flow, in 6 minutes;

$$
j_{L}=0.6 \mathrm{~m} \cdot \mathrm{s}^{-1}, j_{G}=1.90 \mathrm{~m} \cdot \mathrm{s}^{-1} .
$$




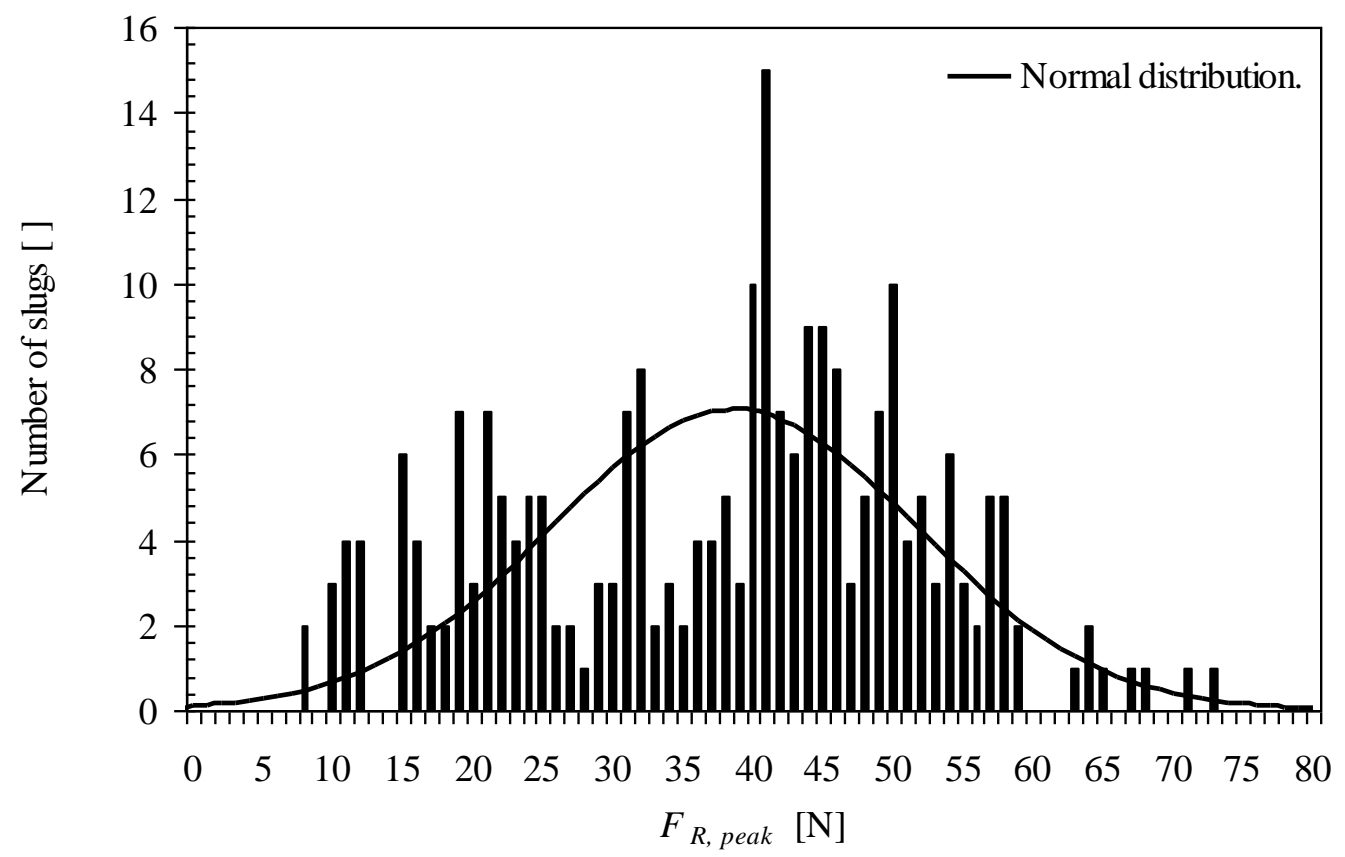

Figure 13 Frequencies of the $F_{R, p e a k} \mathrm{~s}$ acting on a pipe bend in slug flow, in 6 minutes;

$$
j_{L}=0.6 \mathrm{~m} \cdot \mathrm{s}^{-1}, j_{G}=2.02 \mathrm{~m} \cdot \mathrm{s}^{-1} \text {. }
$$

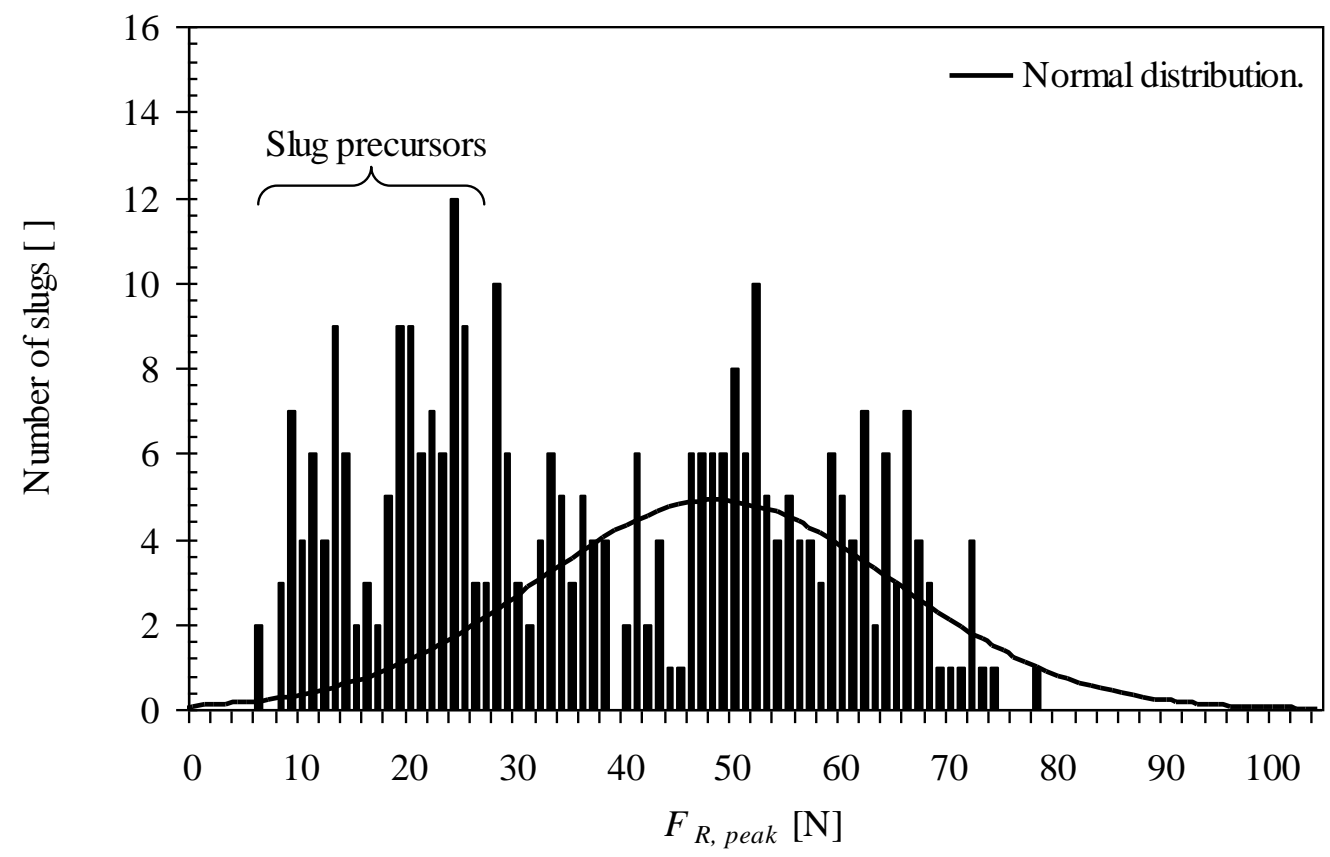

Figure 14 Frequencies of the $F_{R, p e a k} \mathrm{~s}$ acting on a pipe bend in slug flow, in 6 minutes;

$$
j_{L}=0.6 \mathrm{~m} \cdot \mathrm{s}^{-1}, j_{G}=2.36 \mathrm{~m} \cdot \mathrm{s}^{-1} .
$$




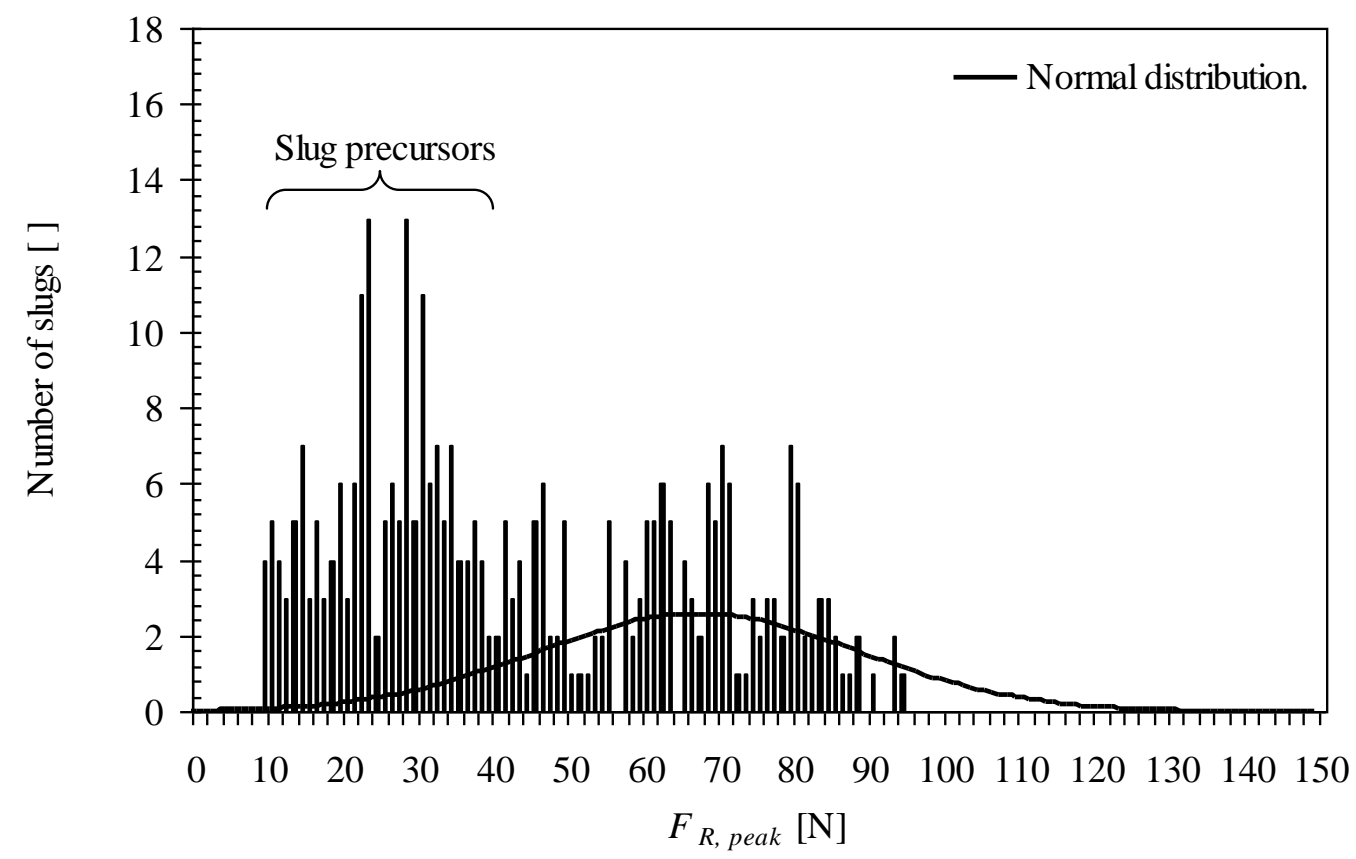

Figure 15 Frequencies of the $F_{R \text {, peak }} \mathrm{s}$ acting on a pipe bend in slug flow, in 6 minutes;

$$
j_{L}=0.6 \mathrm{~m} \cdot \mathrm{s}^{-1}, j_{G}=2.70 \mathrm{~m} \cdot \mathrm{s}^{-1} .
$$

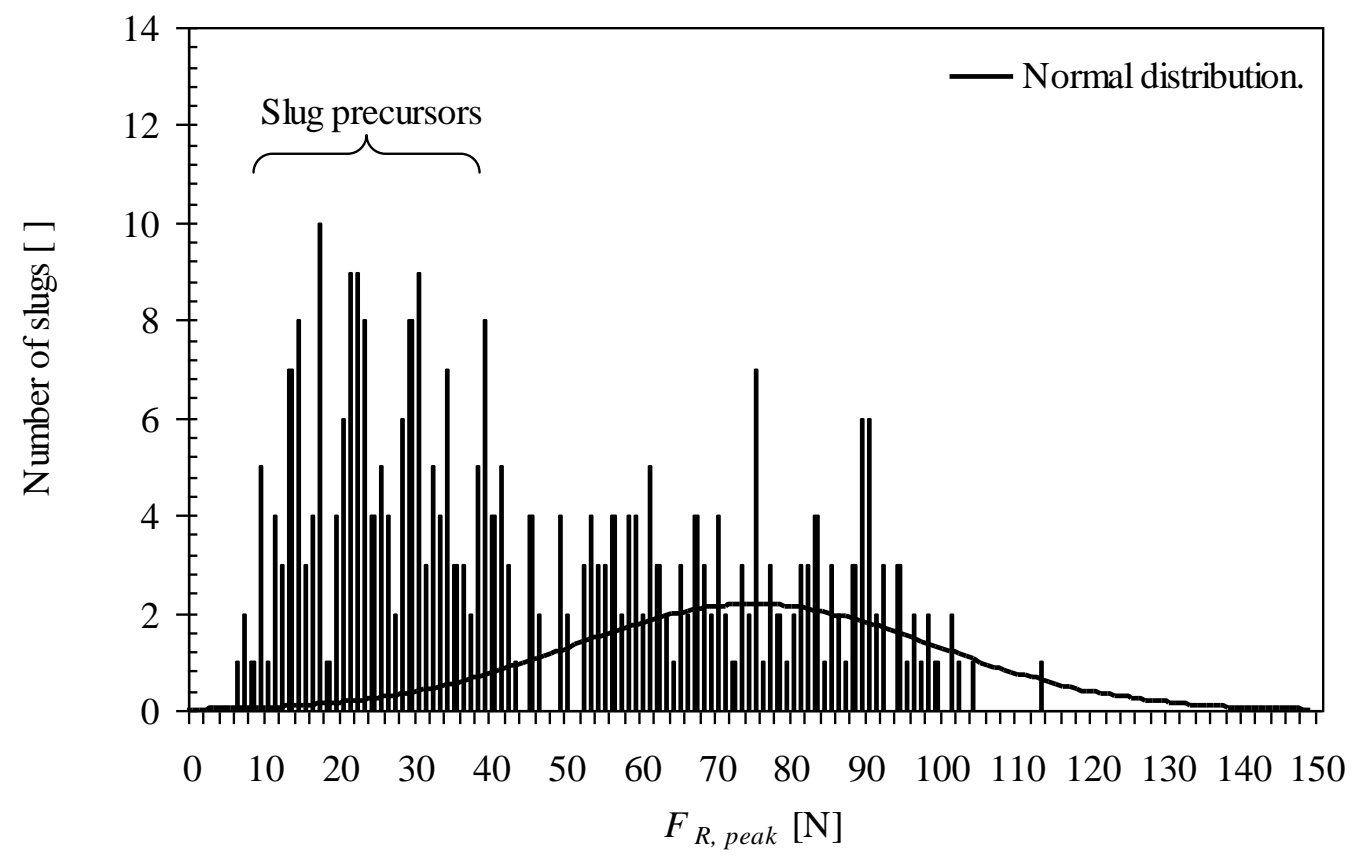

Figure 16 Frequencies of the $F_{R, p e a k} \mathrm{~s}$ acting on a pipe bend in slug flow, in 6 minutes;

$$
j_{L}=0.6 \mathrm{~m} \cdot \mathrm{s}^{-1}, j_{G}=2.87 \mathrm{~m} \cdot \mathrm{s}^{-1} .
$$


Figure 7 to Figure 16 suggest that normal distribution function plausibly describes the distribution of the cyclic forces acting on a pipe bend in slug flow. Following that, a normal distribution (shown in the figures) was fitted by the 'frequency curve' method. In this method, total number of slugs $(N)$, mean of the $F_{R, \text { peak }} \mathrm{s}\left(F_{R, \text { mean }}\right)$ and standard deviation of the $F_{R, \text { peak }} \mathrm{s}\left(F_{R \text {, standard deviation }}\right)$ were identified for each plot i.e. each operating condition; the $F_{R, \text { mean }}$ and $F_{R \text {, standard deviation }}$ were calculated, respectively, as:

$$
\begin{aligned}
& F_{R, \text { mean }}=\frac{\sum_{i=1}^{150} n_{i} F_{R, \text { peak } i}}{N} ; N=\sum_{i=1}^{150} n_{i} \\
& F_{R, \text { standard deviation }}=\sqrt{\frac{\sum_{i=1}^{150} n_{i}\left(F_{R, \text { peak } i}\right)^{2}}{N}-\left(\frac{\left.\sum_{i=1}^{150} n_{i} F_{R, \text { peak } i}\right)^{2}}{N}\right)^{2}}
\end{aligned}
$$

The frequency for each class was then calculated as: $f_{i}=N p_{i}$

where

$$
\begin{aligned}
p_{i}= & \left(\frac{1}{\sqrt{2 \pi F_{R, \text { standard deviation }}}}\right) \times \\
& \left\{\exp \left(-\frac{\left(F_{R, \text { peak } i}-F_{R, \text { standard deviation }}\right)^{2}}{2\left(F_{R, \text { standard deviation }}\right)^{2}}\right)-\exp \left(-\frac{\left(F_{R, \text { peak i-1 }}-F_{R, \text { standard deviation }}\right)^{2}}{2\left(F_{R, \text { standard deviation }}\right)^{2}}\right)\right\}
\end{aligned}
$$

Finally, the normal distribution curve was obtained by plotting the $f_{i}$ against $F_{R, \text { peak } i}$.

Figure 14, Figure 15 and Figure 16 show that there is another 'distribution' in the lower range of the $F_{R, p e a k} \mathrm{~s}$. These $F_{R, p e a k} \mathrm{~s}$ were contributed by the slug precursors, developing 
slugs arriving at the bend due to the relatively short upstream pipe available in the current study (which was limited by the size of the laboratory). Neglecting the slug precursors, the $F_{R, \text { peak }} \mathrm{s}$ acting on pipe bends were found to be well described by normal distribution function.

Interestingly, the $\sqrt{F_{R \text {, mean }}}$ determined from the normal distribution analysis correlates linearly with the flow rates i.e. the total gas and liquid superficial velocity as shown in Figure 17. Similarly, linear relation was obtained for the $\sqrt{F_{R \text {, standard deviation }}}$ and the flow rates in Figure 18.

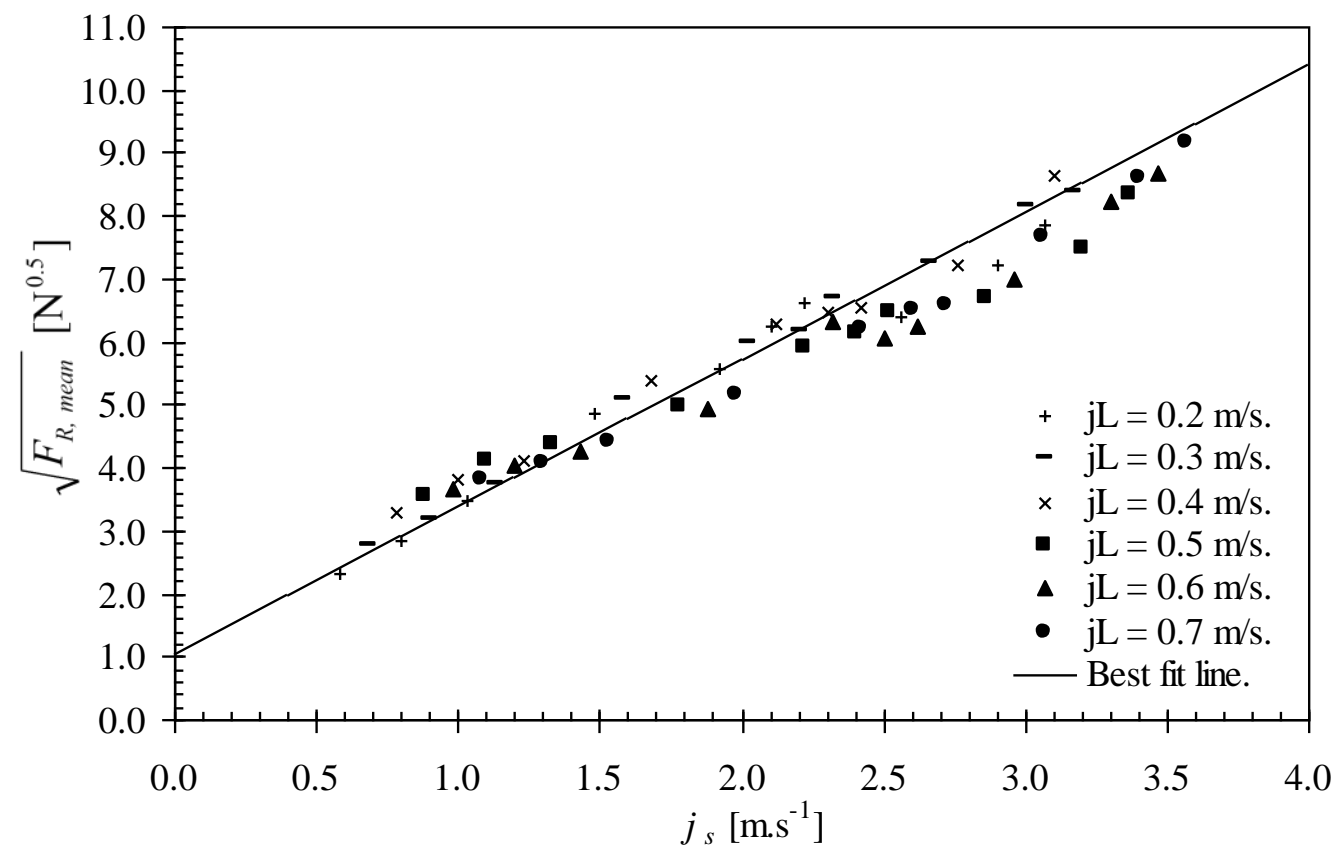

Figure $17 \sqrt{F_{R \text {, mean }}}$ obtained from normal distribution analysis of the $F_{R \text {, peak }} \mathrm{s}$ acting on the pipe bend ( $\phi=90^{\circ} ; D=70 \mathrm{~mm}$ ID; $R / D=1.5$ ) in slug flow in 6-minute durations. 


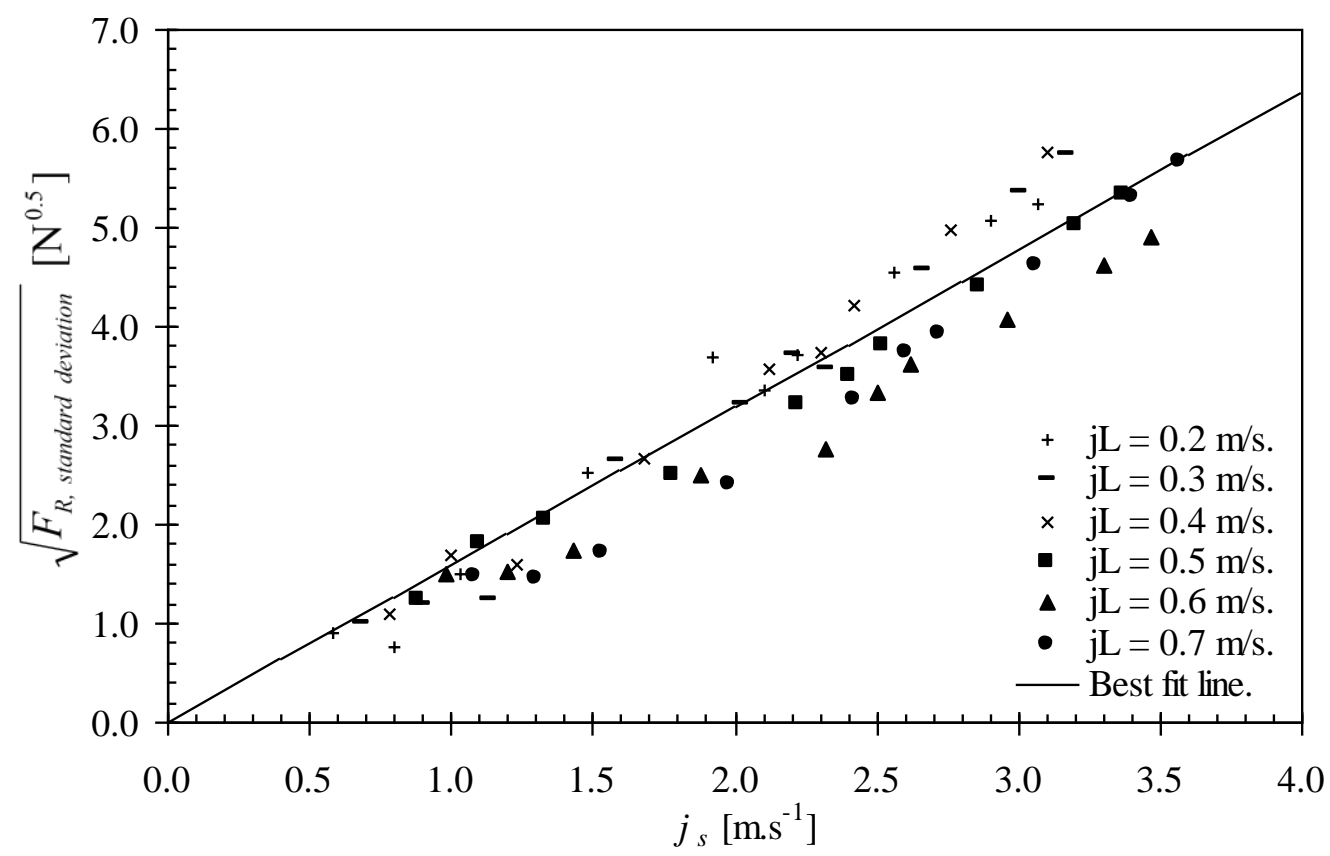

Figure $18 \sqrt{F_{R \text {, standard deviation }}}$ obtained from normal distribution analysis of the $F_{R \text {, peak }} \mathrm{S}$ acting on the pipe bend ( $\left.\phi=90^{\circ} ; D=70 \mathrm{~mm} \mathrm{ID} ; R / D=1.5\right)$ in slug flow in 6-minute durations.

The results obtained from the 6-minute tests suggested that there is an uncertainty in the $\sqrt{F_{R, \text { mean }}}$ and $\sqrt{F_{R, \text { standard deviation }}}$ obtained from the normal distribution analysis although it is believed the 'distribution' at the lower range of forces were slug precursors. To prove this conclusion is sensible, the experiments have therefore been repeated with the test duration increased from 6 minutes to 30 minutes.

\subsection{0-minute tests}

Figure 19 to Figure 28 show a series of histogram plots, of number of occurrence of each peak (resultant) force acting on the bend in 30 minutes, obtained for $j_{L}=0.6 \mathrm{~m} \cdot \mathrm{s}^{-1}$ and $0.38 \mathrm{~m} . \mathrm{s}^{-1} \leq j_{G} \leq 2.87 \mathrm{~m} \cdot \mathrm{s}^{-1}$. Again, similar plots were obtained for other flow rates used in the current study; where $0.2 \mathrm{~m} . \mathrm{s}^{-1} \leq j_{L} \leq 0.7 \mathrm{~m} . \mathrm{s}^{-1}$ and $0.38 \mathrm{~m} . \mathrm{s}^{-1} \leq j_{G} \leq 2.87 \mathrm{~m} . \mathrm{s}^{-1}$. 


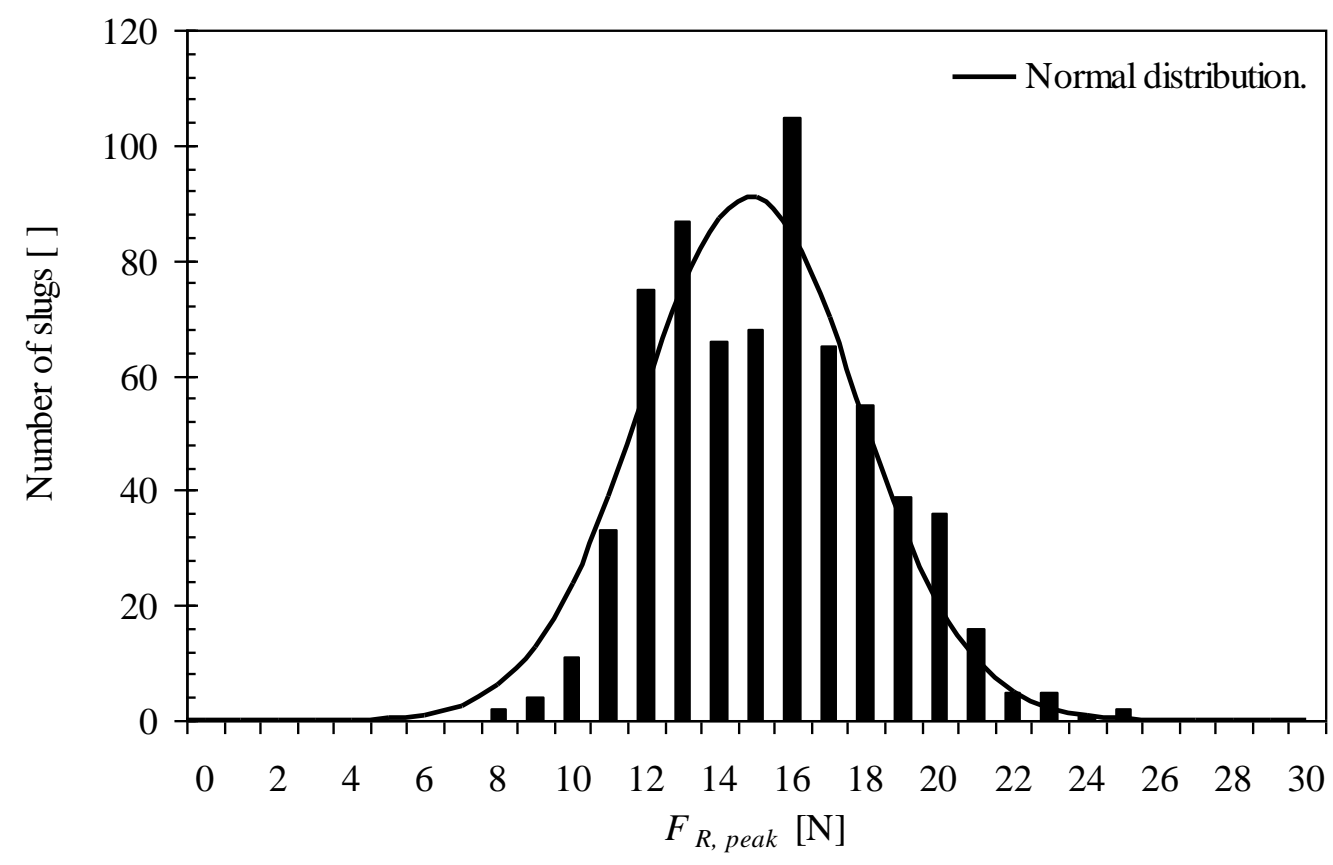

Figure 19 Frequencies of the $F_{R \text {, peak }} \mathrm{s}$ acting on a pipe bend in slug flow, in 30 minutes; $j_{L}=0.6 \mathrm{~m} . \mathrm{s}^{-1}, j_{G}=0.38 \mathrm{~m} . \mathrm{s}^{-1}$.

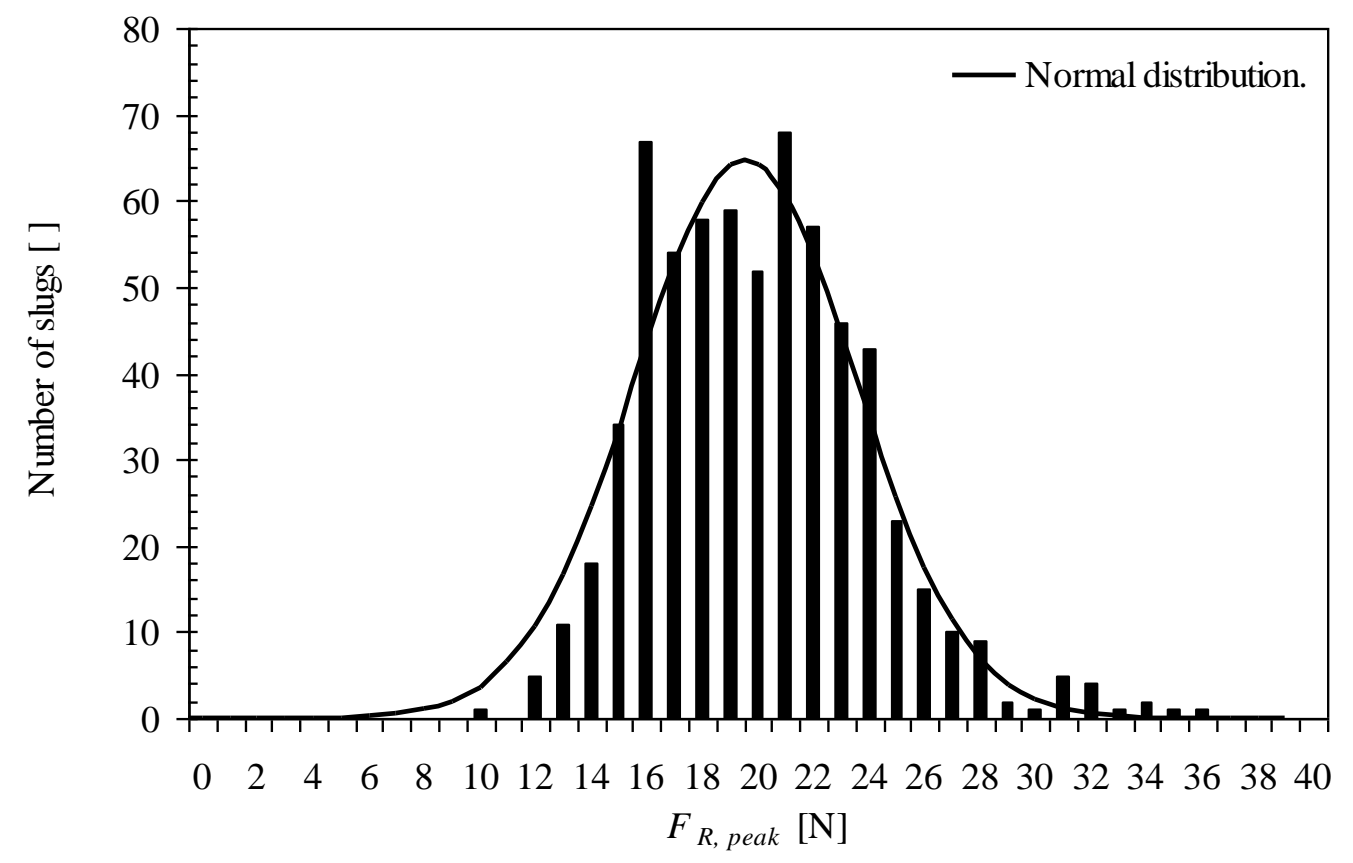

Figure 20 Frequencies of the $F_{R, \text { peak }} \mathrm{s}$ acting on a pipe bend in slug flow, in 30 minutes; $j_{L}=0.6 \mathrm{~m} \cdot \mathrm{s}^{-1}, j_{G}=0.60 \mathrm{~m} \cdot \mathrm{s}^{-1}$. 


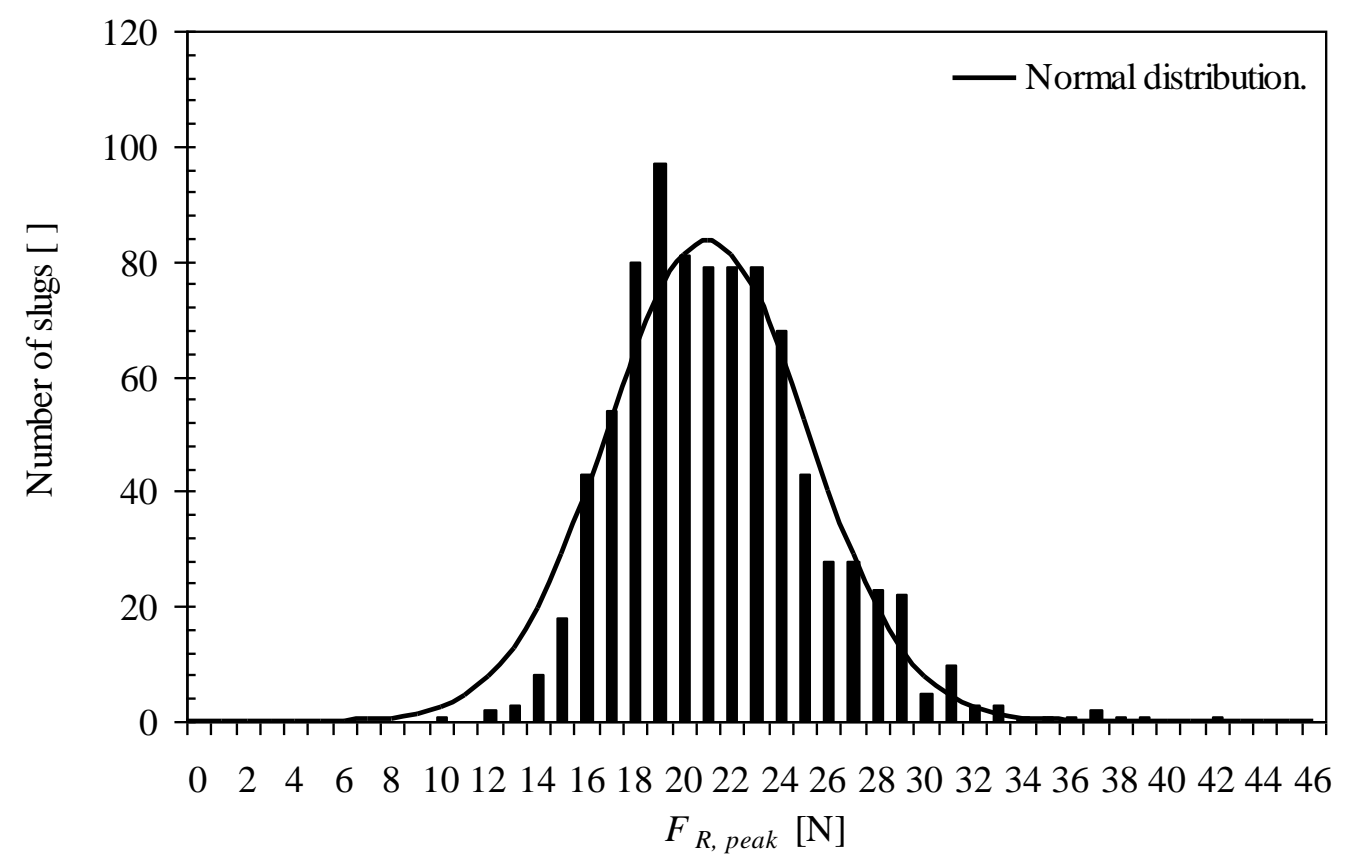

Figure 21 Frequencies of the $F_{R, \text { peak }} \mathrm{s}$ acting on a pipe bend in slug flow, in 30 minutes; $j_{L}=0.6 \mathrm{~m} . \mathrm{s}^{-1}, j_{G}=0.83 \mathrm{~m} \cdot \mathrm{s}^{-1}$.

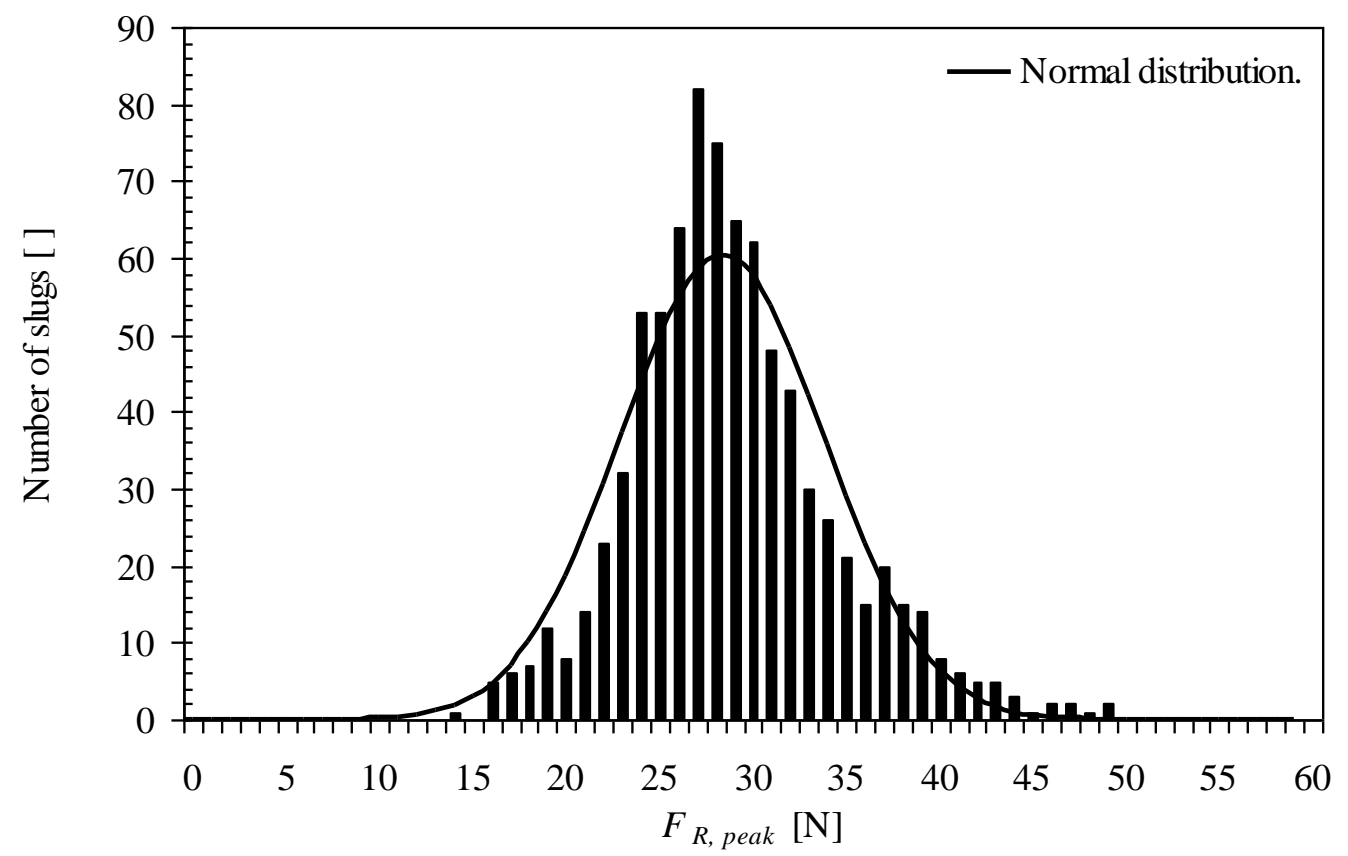

Figure 22 Frequencies of the $F_{R, \text { peak }} \mathrm{s}$ acting on a pipe bend in slug flow, in 30 minutes;

$$
j_{L}=0.6 \mathrm{~m} \cdot \mathrm{s}^{-1}, j_{G}=1.28 \mathrm{~m} \cdot \mathrm{s}^{-1} .
$$




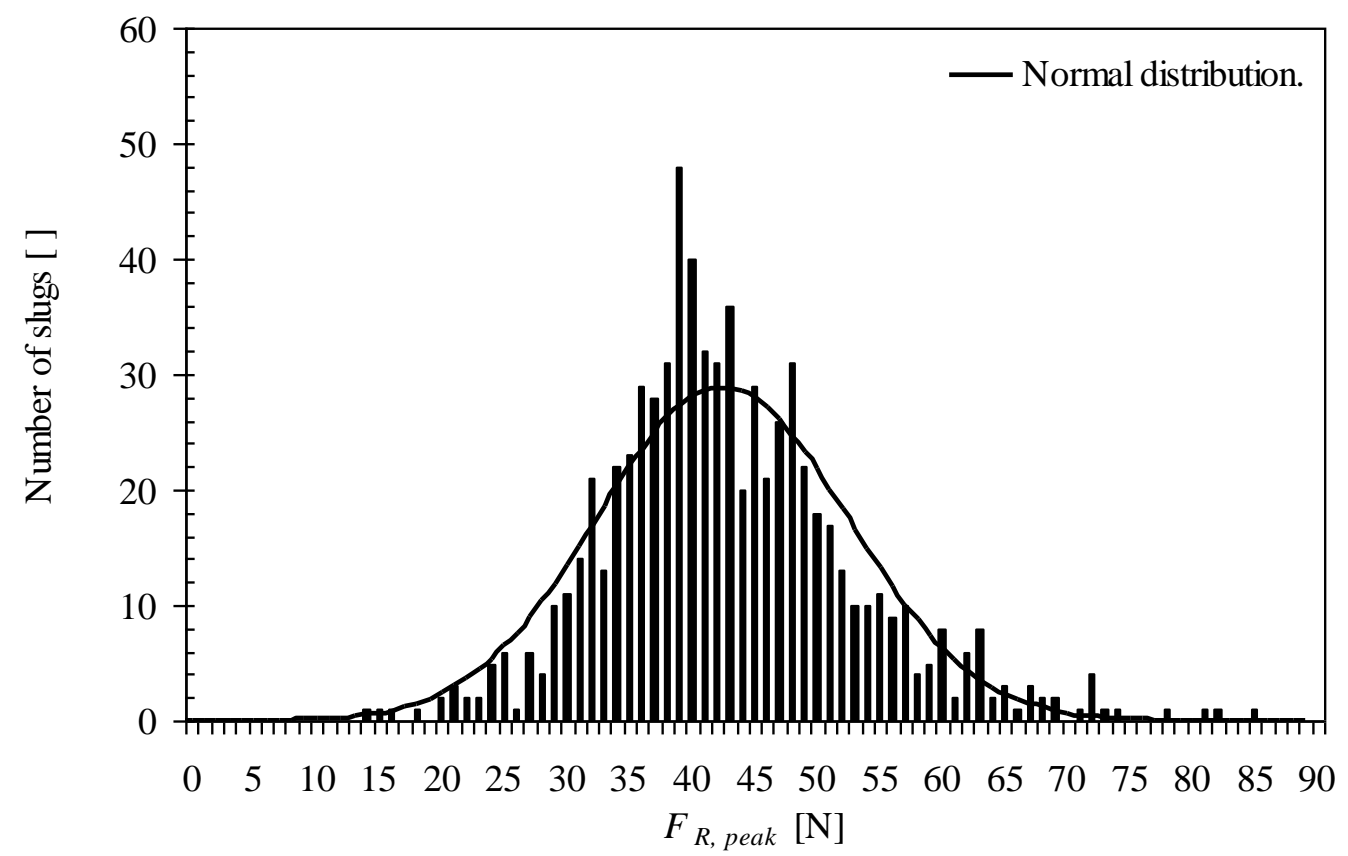

Figure 23 Frequencies of the $F_{R \text {, peak }} \mathrm{s}$ acting on a pipe bend in slug flow, in 30 minutes; $j_{L}=0.6 \mathrm{~m} . \mathrm{s}^{-1}, j_{G}=1.72 \mathrm{~m} . \mathrm{s}^{-1}$.

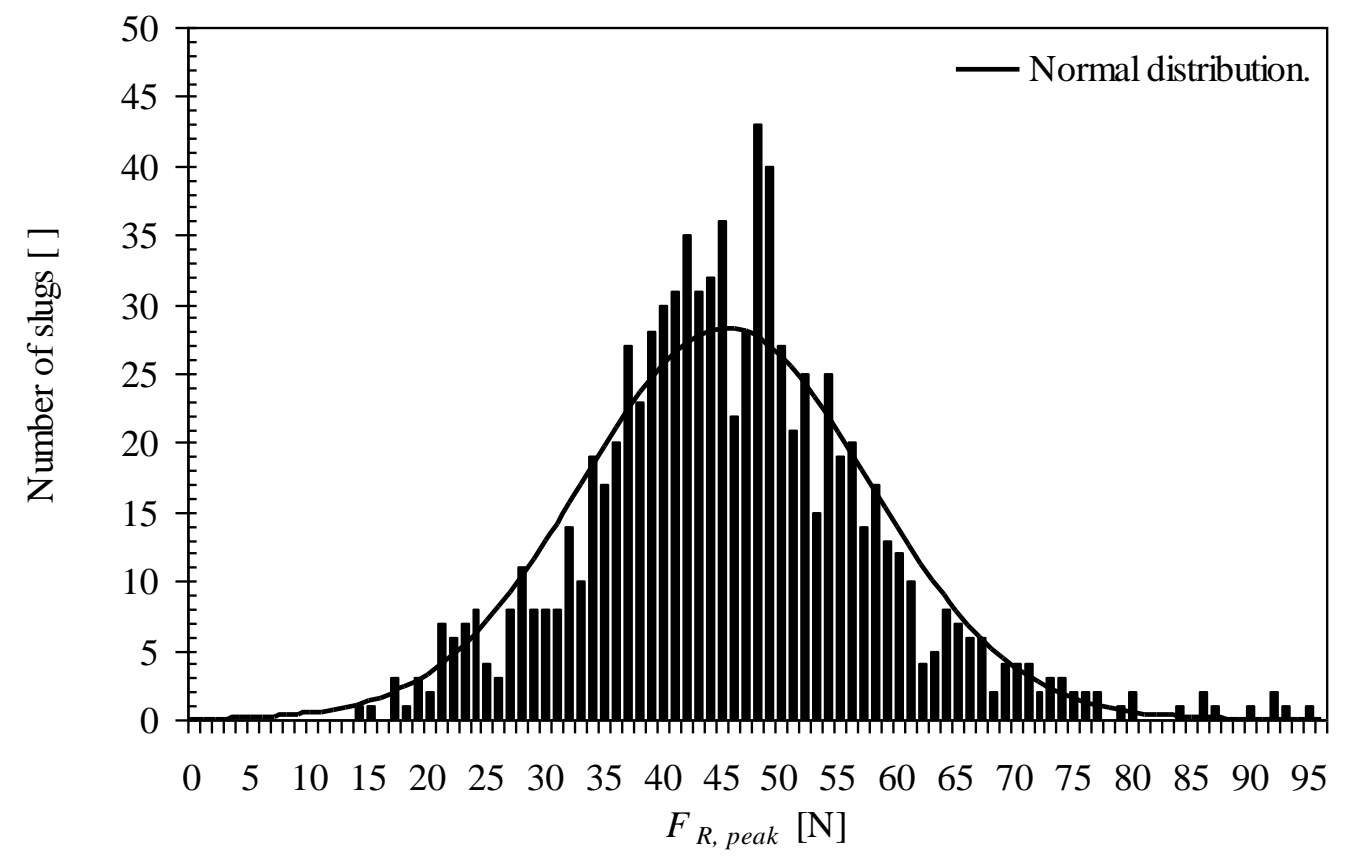

Figure 24 Frequencies of the $F_{R, \text { peak }} \mathrm{s}$ acting on a pipe bend in slug flow, in 30 minutes;

$$
j_{L}=0.6 \mathrm{~m} \cdot \mathrm{s}^{-1}, j_{G}=1.90 \mathrm{~m} \cdot \mathrm{s}^{-1} .
$$




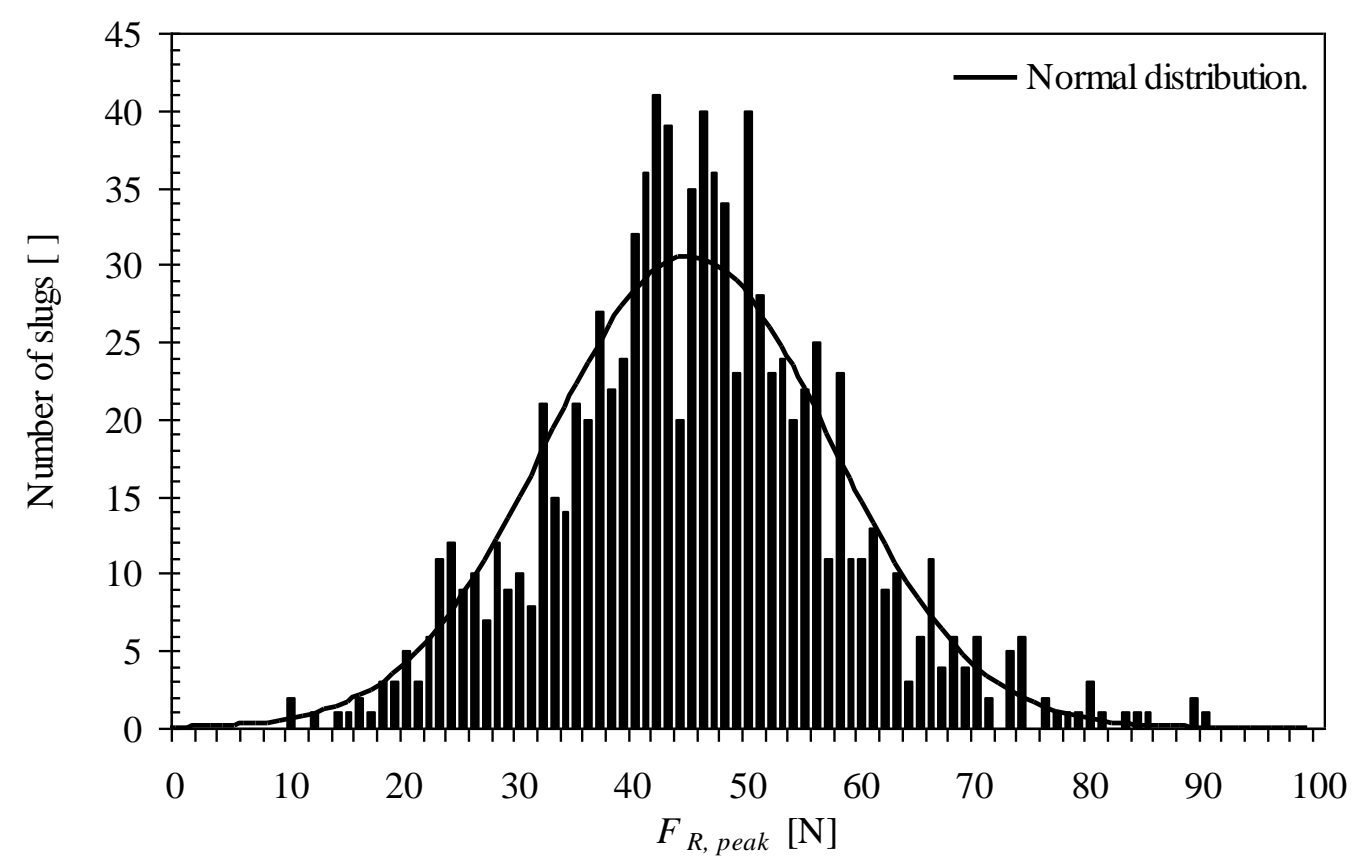

Figure 25 Frequencies of the $F_{R \text {, peak }} \mathrm{s}$ acting on a pipe bend in slug flow, in 30 minutes; $j_{L}=0.6 \mathrm{~m} . \mathrm{s}^{-1}, j_{G}=2.02 \mathrm{~m} . \mathrm{s}^{-1}$.

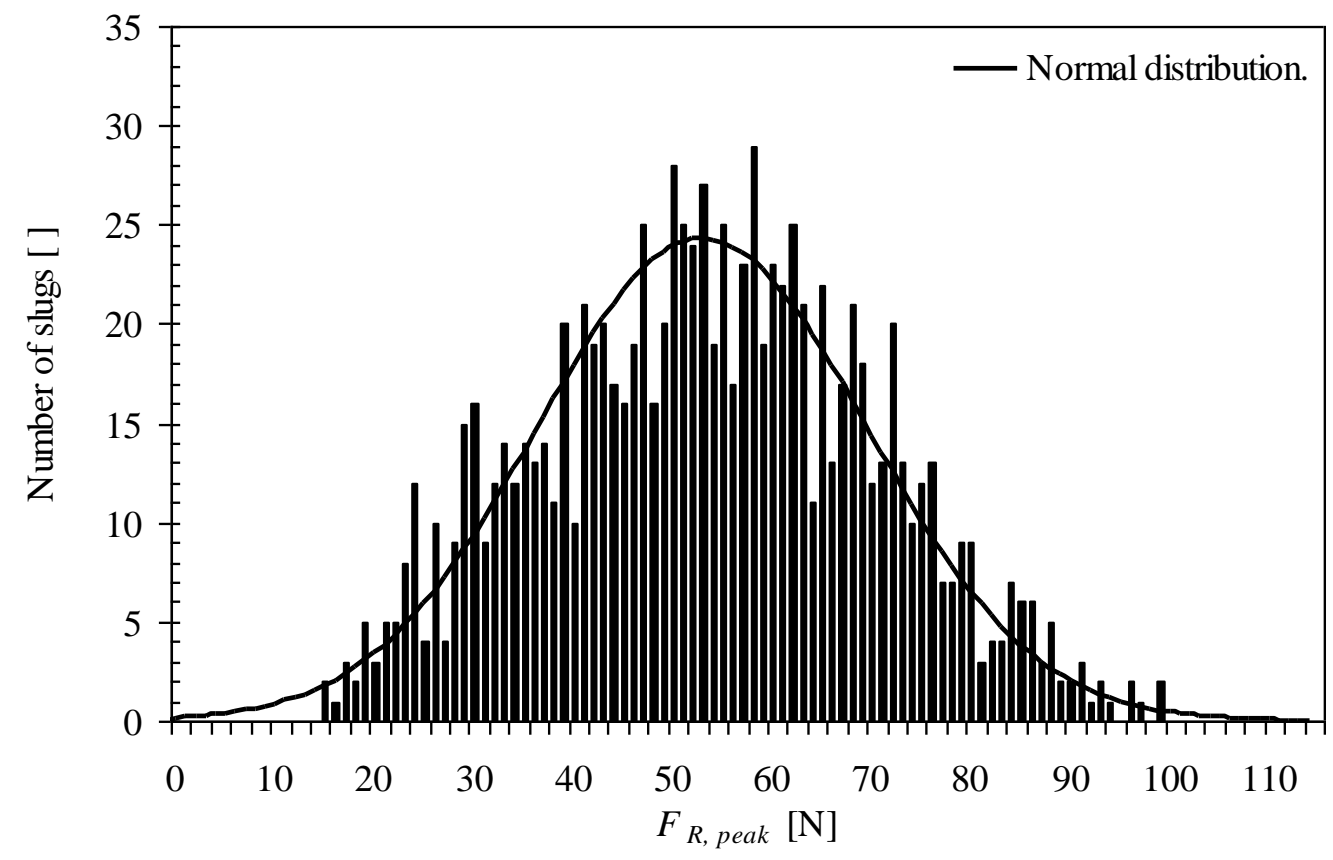

Figure 26 Frequencies of the $F_{R, \text { peak }} \mathrm{s}$ acting on a pipe bend in slug flow, in 30 minutes; $j_{L}=0.6 \mathrm{~m} . \mathrm{s}^{-1}, j_{G}=2.36 \mathrm{~m} \cdot \mathrm{s}^{-1}$. 


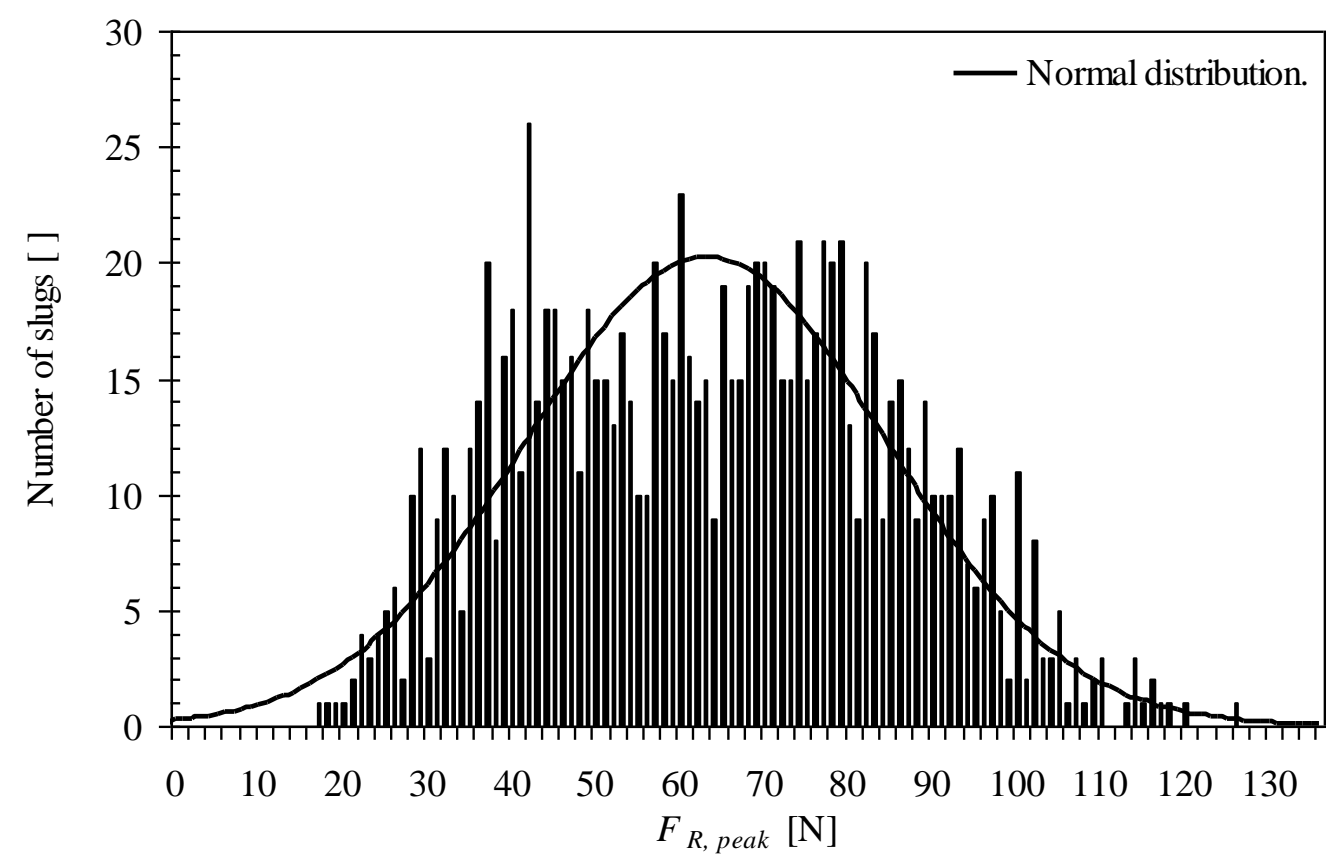

Figure 27 Frequencies of the $F_{R \text {, peak }} \mathrm{s}$ acting on a pipe bend in slug flow, in 30 minutes; $j_{L}=0.6 \mathrm{~m} . \mathrm{s}^{-1}, j_{G}=2.70 \mathrm{~m} . \mathrm{s}^{-1}$.

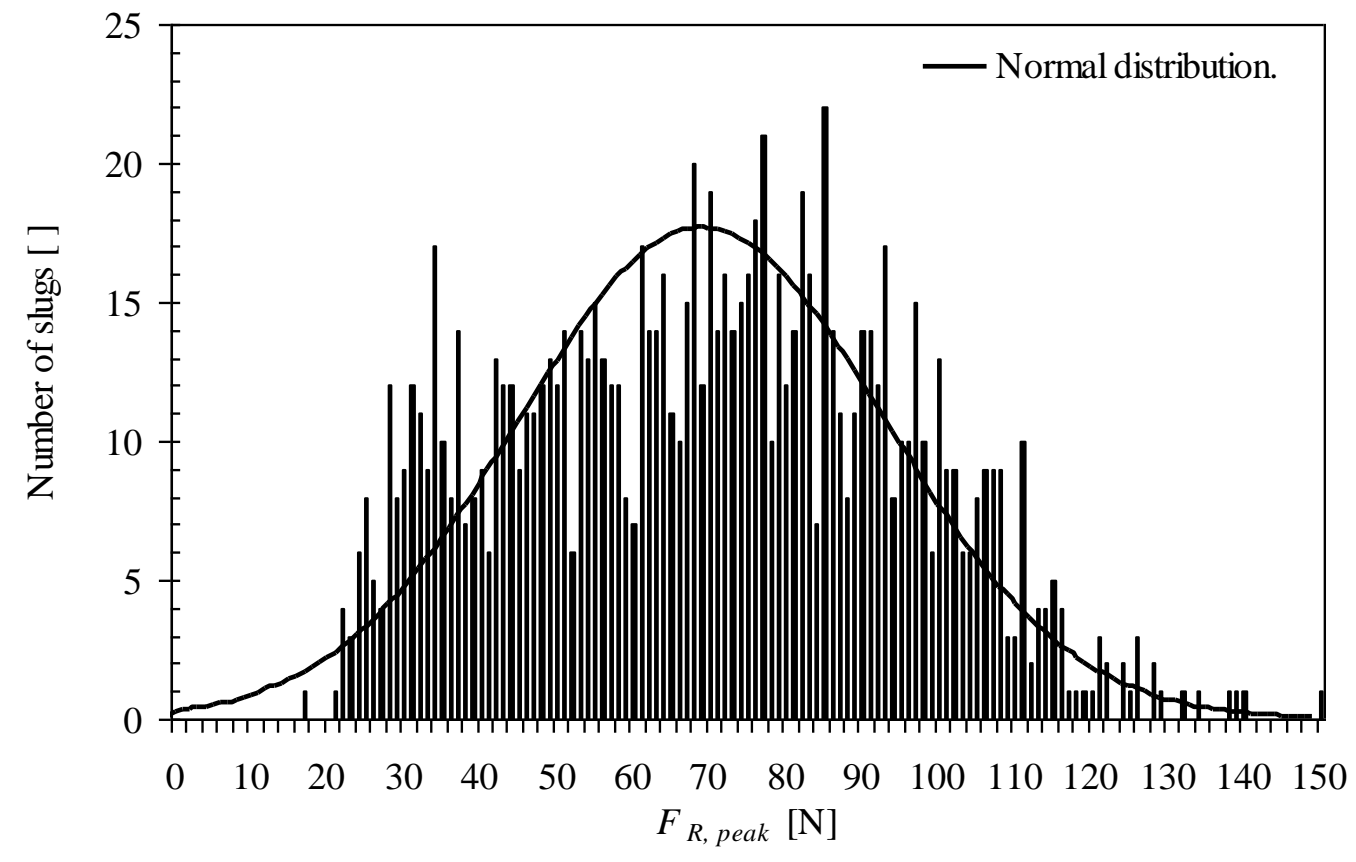

Figure 28 Frequencies of the $F_{R \text {, peak }} \mathrm{s}$ acting on a pipe bend in slug flow, in 30 minutes; $j_{L}=0.6 \mathrm{~m} . \mathrm{s}^{-1}, j_{G}=2.87 \mathrm{~m} . \mathrm{s}^{-1}$. 
Figure 19 to Figure 28 with 5 times the sample size in 6-minute tests, confirmed the earlier findings that (1) normal distribution function plausibly describes the distribution of the cyclic force acting on a pipe bend in slug flow, (2) the 'distributions' in the lower range of the $F_{R, \text { peak }} \mathrm{s}$ in Figure 14, Figure 15 and Figure 16 were contributed by the slug precursors. Again, the $\sqrt{F_{R, \text { mean }}}$ determined from the normal distribution analysis on $F_{R, \text { peak }} \mathrm{S}$ obtained from the 30-minute tests, and the corresponding $\sqrt{F_{R, \text { standard deviation }}}$ correlates linearly with the flow rates. Besides that, $\sqrt{F_{R, \text { mean }}}$ and $\sqrt{F_{R \text {, standard deviation }}}$ obtained from the 6-minute tests agree with the results from the 30 -minute tests. This is shown in Figure 29 and Figure 30.

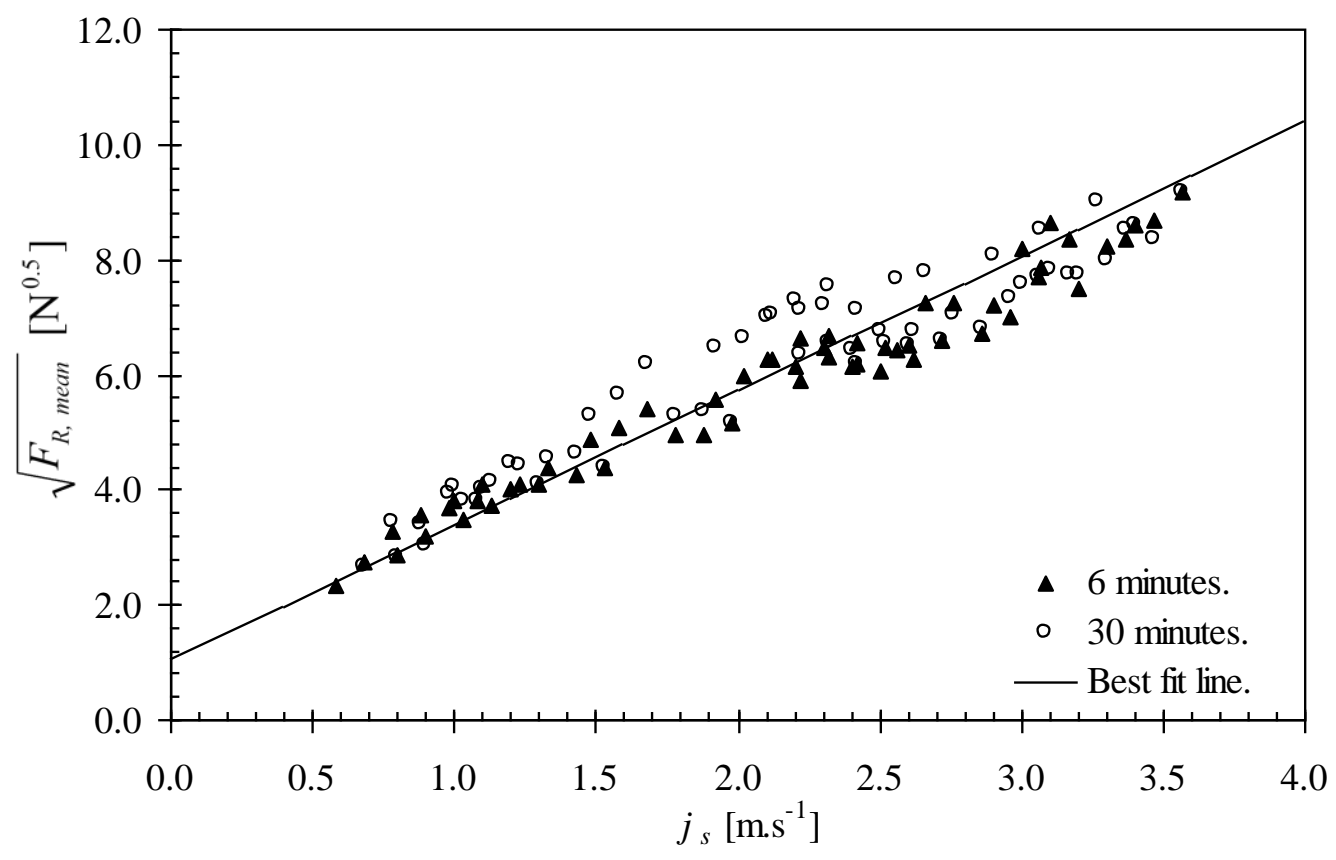

Figure $29 \sqrt{F_{R, \text { mean }}}$ obtained from 6-minute tests in comparison to $\sqrt{F_{R, \text { mean }}}$ obtained from 30-minute tests. 


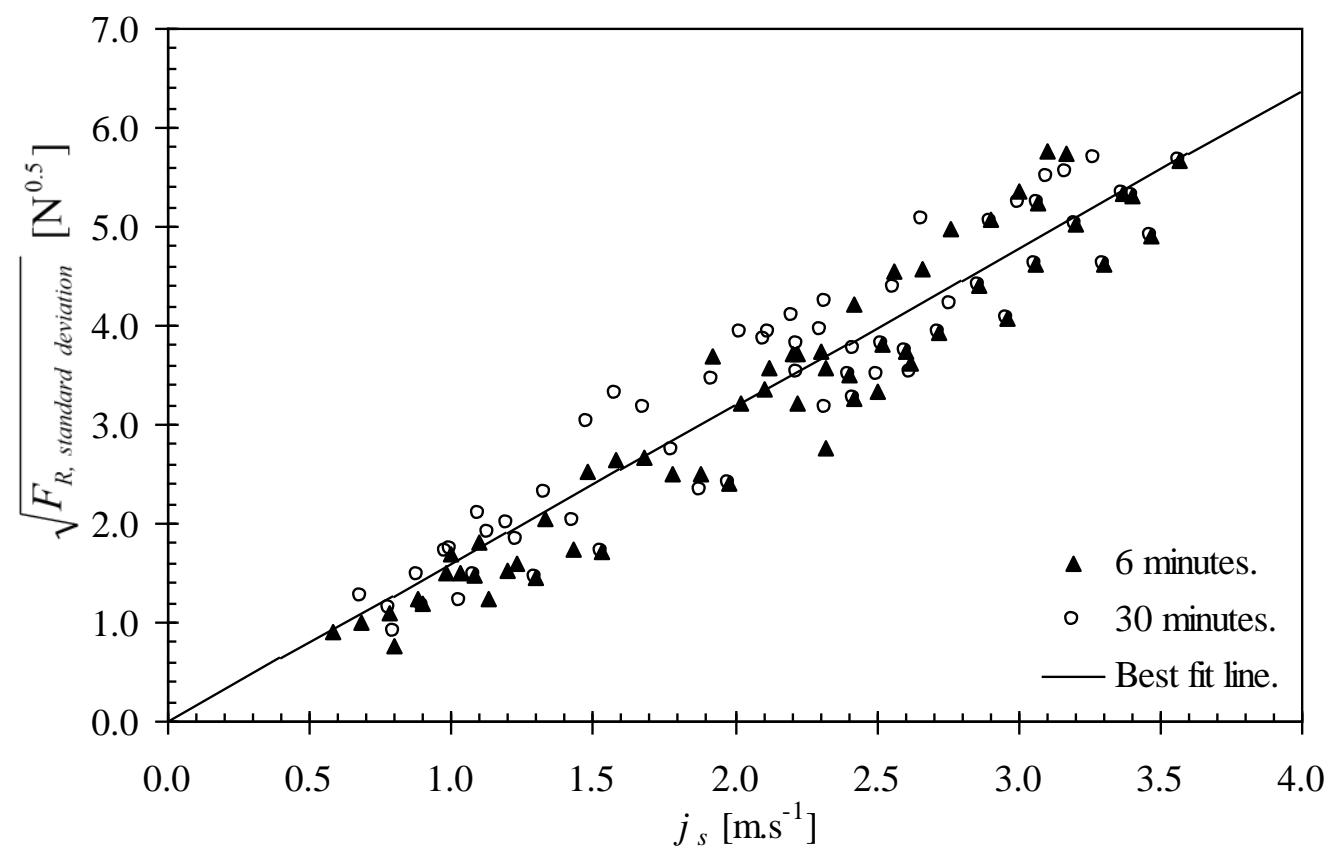

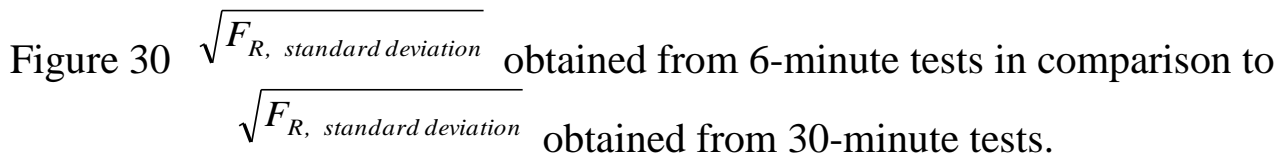

\section{Prediction by the Piston Flow Model (PFM)}

\subsection{Experimental results compared with prediction by the Piston Flow Model (PFM)}

The experimental result and distribution analysis of the $F_{R \text {, peak }} \mathrm{s}$ acting on pipe bends have shown that the peak force data collected can give a prediction of the $F_{R \text {, peak }}$ distribution to be expected throughout the operating duration.

On the other hand, the Piston Flow Model (PFM) proposed by Tay and Thorpe (2002, 2004,2014 ) has shown to be able to predict the maximum force, $F_{R, \max }$ acting on pipe bends at various flow rates i.e. the largest force among the peak forces, $F_{R \text {, peak }}$ at an operating condition. In PFM, Tay and Thorpe (2002, 2004, 2014) proposed a hypothetical slug flow of a piston flow of pure gas followed by a piston flow of pure 
liquid, flow at a constant and uniform velocity, $u_{s}$ (where $u_{s}$ is slug velocity and $j_{s}$ is superficial mixture velocity; $u_{s}=1.2 j_{s}+0.41$ and $j_{s}=j_{L}+j_{G}$ ) and, assumed one, average, value of pressure applies at all points of the cross section of the pipe. As discussed by Tay \& Thorpe $(2002,2004,2014)$, the prediction of slug lengths is still under research; the measured slug length is used in PFM calculations.

The PFM prediction is compared with the experimental results from 6-minute tests and 30 minute tests in Figure 31. PFM calculates forces by considering alternate liquid holdup and gas holdup of 1.0 and 0.0. Tay and Thorpe (2004, 2014) adjusted their force measurements for the corresponding liquid hold-up measured for air-water flow; this adjustment is made in the experimental data plotted in Figure 31.

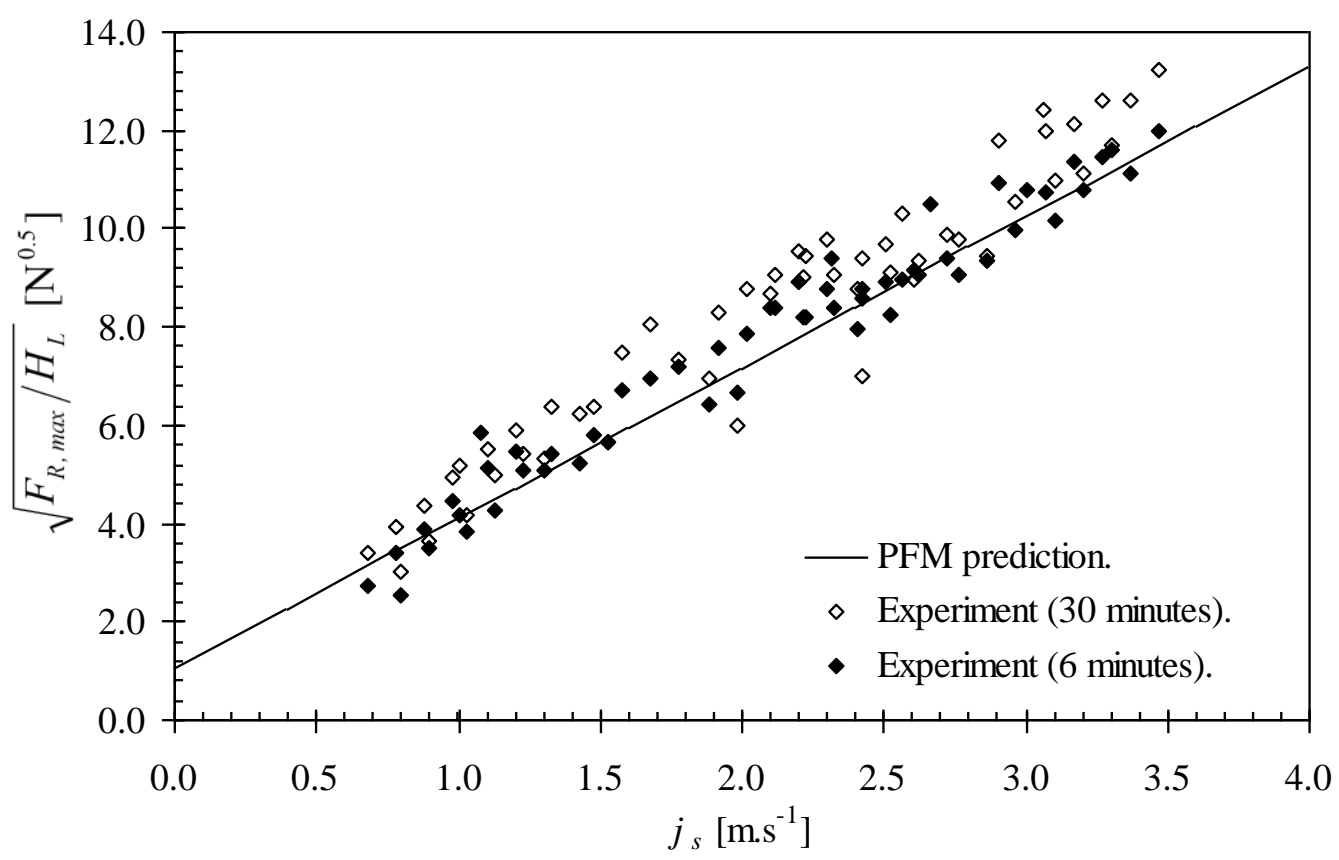

Figure 31 PFM prediction of $\sqrt{F_{R, \max }}$ in air-water slug flow. 
From the above information, a diagram as shown in Figure 32 can be sketched for a particular operation (i.e. for a $j_{L}$ and $j_{G}$ etc.). 'Cumulative damage' due to $F_{R \text {, peak } i}$ can be calculated as $\sum_{i=1}^{\infty} \frac{N p_{i}}{N_{i}}$ where $p_{i}$ is the probability of $F_{R, \text { peak } i}$ (for $F_{\text {endurance limit }} \leq F_{R, \text { peak } i} \leq F_{R, \text { max }}$ ) to occur. Associated with each value is an expected number of cycles to failure, $N_{i}$ (found from S-N curve). $N$ is the total number of peak force cycles over the operating duration.

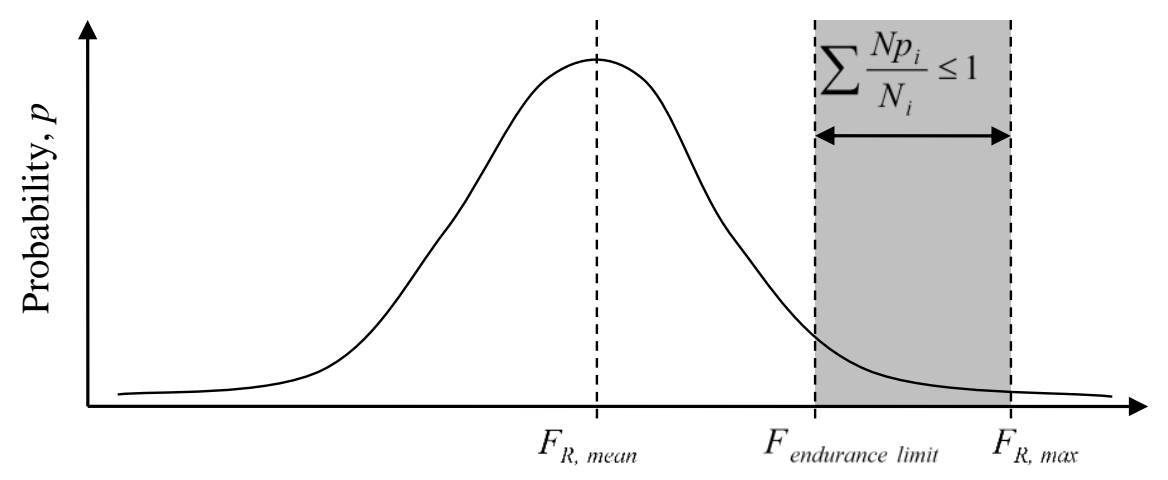

Figure 32 Sample distribution of the $F_{R \text {, peak }} \mathrm{s}$ on a pipe bend at a $j_{L}$ and $j_{G}$.

It is certainly common for a system to operate at variable flow rates. Under this circumstance, a few plots such as that in Figure 32 at the corresponding operating flow rates and conditions must be considered. In this case, the 'cumulative damage' should theoretically be $\sum_{\text {operating condition, } j=1}^{j_{\max }}\left(\sum_{i=1}^{\infty}\left(\frac{N p_{i}}{N_{i}}\right)\right)_{j} ; j=1,2, \ldots, j_{\max }$ and $i=1,2, \ldots, \infty$. Hence the fatigue life limit of a pipe bend or pipe fittings in slug flow is calculated. However, this can be done only if $F_{R, \text { mean } j}$ and $F_{R \text {, standard deviation } j}$ are known. 


\subsection{Predicting the mean of the $F_{R, \text { peak }} S\left(F_{R, \text { mean }}\right)$}

PFM has been shown to be able to predict the maximum resultant force, $\sqrt{F_{R, \max P F M \text { at } u_{s}}}$, when slug velocity, $u_{s}$ that is the maximum velocity a slug can move in a pipe, is used. $\sqrt{F_{R \text {, mean experiment }}}$ is compared to $\sqrt{F_{R, \text { max PFM at } u_{s}}}$ in Figure 33 ; the $\sqrt{F_{R, \text { mean experiment }}}$ is shown to be lower than $\sqrt{F_{R, \max P F M} \text { at } u_{s}}$ and drops significantly below the line at $j_{s}>2.5 \mathrm{~m} \cdot \mathrm{s}^{-1}$.

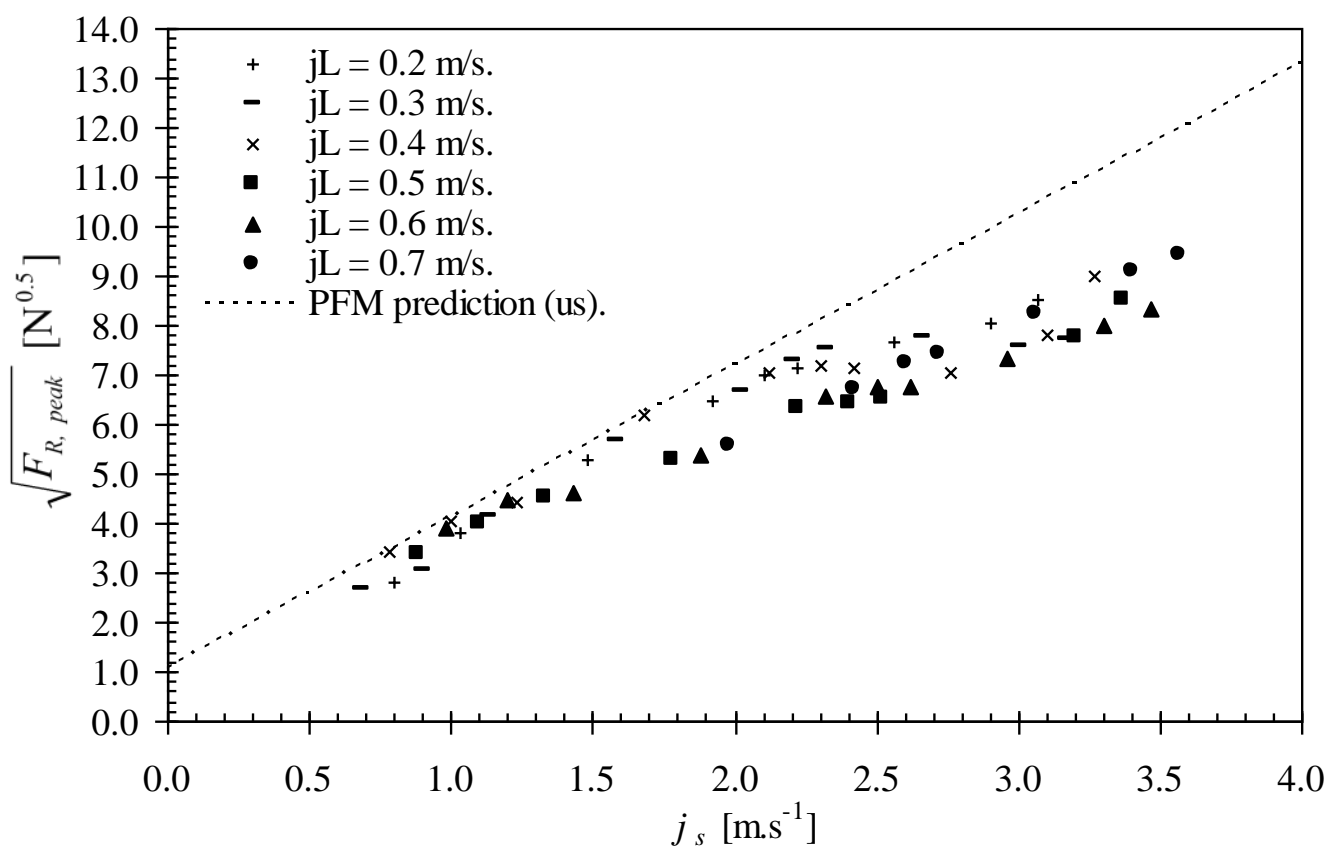

Figure $33 \sqrt{F_{R \text {, mean experiment }}}$ in comparison to $\sqrt{F_{R, \max P F M \text { at } u_{s}}}$.

A similar phenomenon in the maximum force measurements was reported (Tay and Thorpe, 2014). It was shown that this is due to the bubbles in the liquid slug i.e. the liquid hold-up in the liquid slug was significantly lower than one; in effect the density in the liquid slug is less than density of the liquid used. 
As discussed, Tay and Thorpe $(2004,2014)$ adjusted their force measurements for the corresponding liquid hold-up measured for air-water flow and this adjustment brought the force measurements back to the PFM line. Following the same method, the measured liquid hold-up (Figure 34) is used to adjust the force measurements by plotting $\sqrt{F_{R, \text { mean }} / H_{L}}$ against $j_{s}$ as shown in Figure 35 . Figure 35 shows that the data, $\sqrt{F_{R \text {, mean experiment }} / H_{L}}$ is lower than $\sqrt{F_{R, \max P F M} \text { at } u_{s}}$ but close to it. Therefore, it is thought that the $\sqrt{F_{R, \text { mean }} / H_{L}}$ may plausibly be predicted by PFM, by considering slugs flow down the pipe at the total superficial velocity, $j_{s}$. Therefore, PFM has been used to

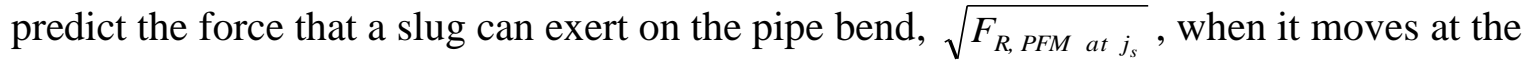
total superficial velocity $\left(j_{S}\right)$. The $\sqrt{F_{R, \text { mean experiment }} / H_{L}}$ is compared to $\sqrt{F_{R, P F M \text { at } j_{s}}}$ and $\sqrt{F_{R, \max P F M} \text { at } u_{s}}$ in Figure 35 . Figure 35 shows that $\sqrt{F_{R \text {, mean experiment }} / H_{L}}$ falls between $\sqrt{F_{R, P F M \text { at } j_{s}}}$ and $\sqrt{F_{R, \max P F M \text { at } u_{s}}}$.

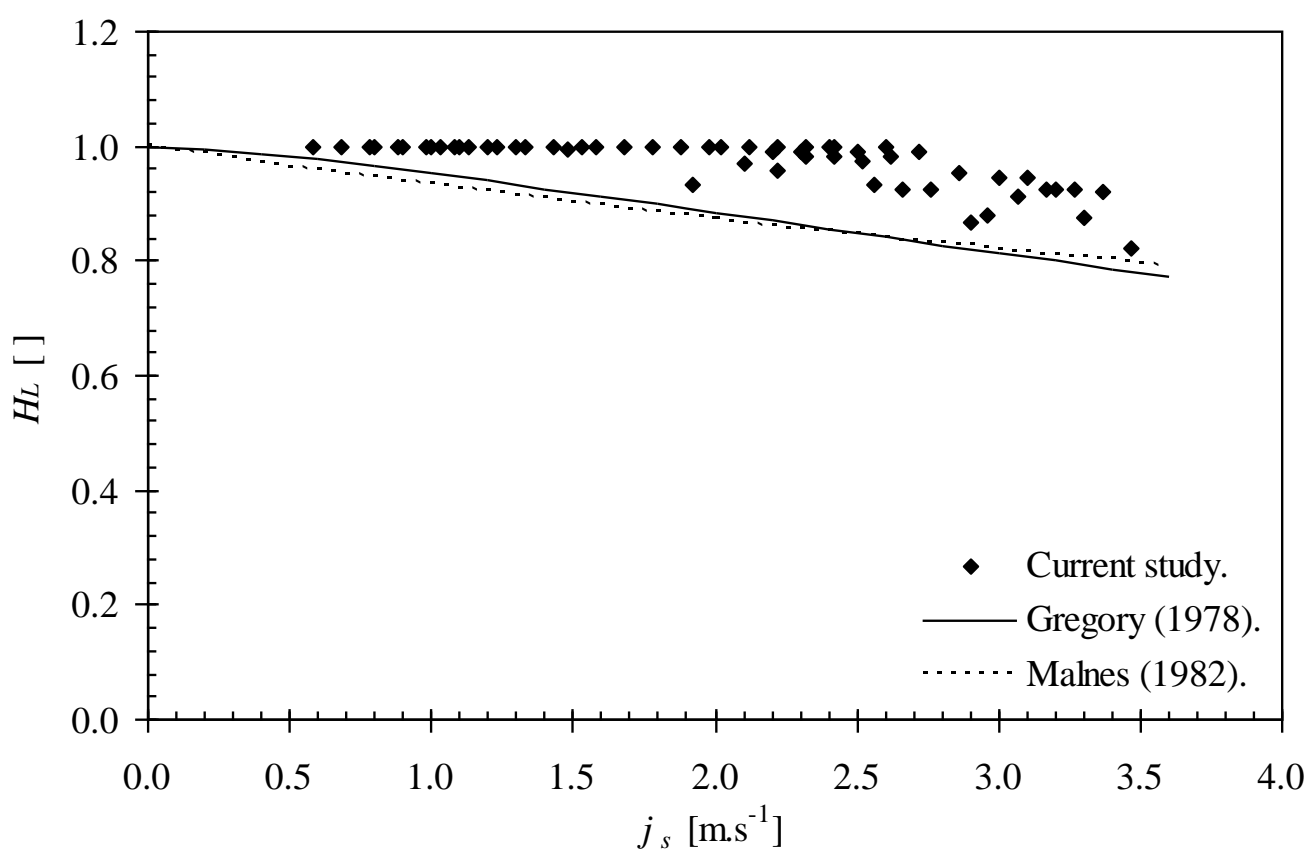


Figure 34 Liquid hold-up in the liquid slug body measured in the current study in comparison to the predictions of Gregory (1978) and Malnes (1982).

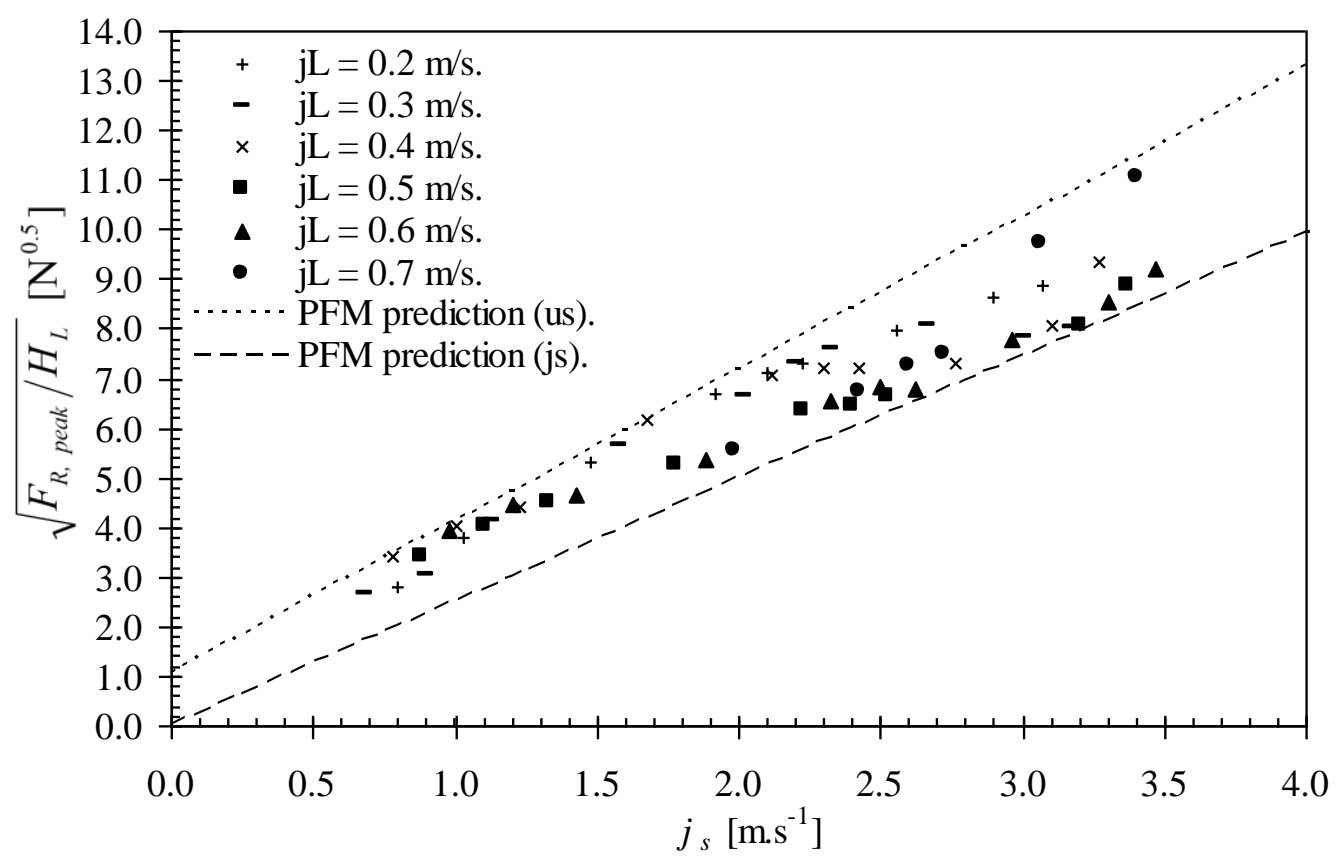

Figure $35 \sqrt{F_{R, \text { mean experiment }} / H_{L}}$ in comparison to $\sqrt{F_{R, P F M} \text { at } j_{s}}$ and $\sqrt{F_{R, \text { max PFM at } u_{s}}}$.

Interestingly, linear regression of the data gives a best fit line of the same slope as $\sqrt{F_{R, P F M \text { at } j_{s}}}$ against $j_{s}$, but the same intercept at ordinate as $\sqrt{F_{R, \max P F M} \text { at } u_{s}}$ against $j_{s}$ . This is shown in Figure 36, that:

$$
\begin{aligned}
& \sqrt{F_{R, \text { max } P F M \text { at } u_{s}}}=M_{\text {max }} j_{s}+C_{\text {max }} \\
& \sqrt{F_{R, P F M \text { at js }}}=M_{j_{s}} j_{s} \\
& \sqrt{F_{R, \text { mean }} / H_{L}}=M_{j_{s}} j_{s}+C_{\max }
\end{aligned}
$$




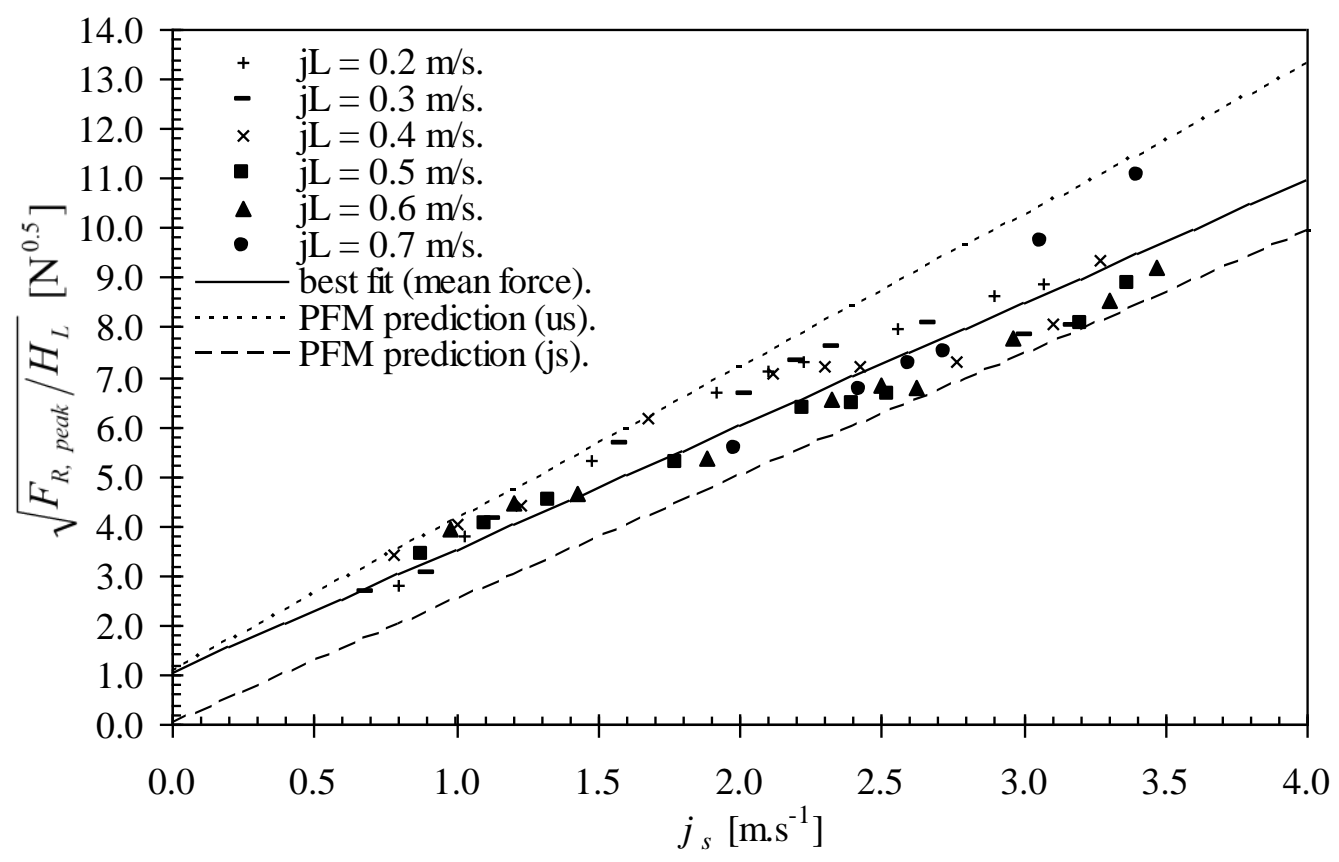

Figure $36 \sqrt{F_{R, \text { mean }} / H_{L}}$ as a linear function of $j_{s}$.

Therefore, $F_{R, \text { mean }} / H_{L}$ can be predicted using PFM. $F_{R, \text { mean }}$ can then be obtained by multiplying $F_{R, \text { mean }} / H_{L}$ with $H_{L} \cdot H_{L}$ can be approximated using the correlations available in literature (Gregory et al., 1978 and Malnes, 1982).

Gregory et al. (1978) used capacitance-type liquid-volume-fraction sensors to provide a continuous record of the in situ liquid volume fraction. From their experimental data on air-oil slug flow in horizontal $2.58 \mathrm{~cm}$ and $5.12 \mathrm{~cm}$ ID pipes, they suggested that:

$$
H_{L}=\frac{1}{1+\left(j_{s} / 8.66\right)^{1.39}}
$$

where the mixture velocity, $j_{s}$ has units of metres per second. In spite of the fact that this correlation does not include the effects of fluid properties, pipe diameter and inclination, 
and its multiplier is dimensional i.e. 8.66, it is frequently used because of its simplicity. Malnes (1982) based his correlation on the same data as Gregory et al. (1978) proposed that:

$$
H_{L}=1-\frac{j_{s}}{83\left(\frac{g \sigma}{\rho_{L}}\right)^{1 / 4}+j_{s}}
$$

It is not clear how Malnes (1982) does this since only oil was used, $\rho_{L}$ and $\sigma$ were not varied. Malnes (1982) also predicts no effect of pipe size and inclination.

Figure 34 shows the experimental data obtained in the current study, in comparison to the predictions of Gregory et al. (1978) and Malnes (1982); although the agreement is not encouraging, these are the most frequently used correlations. For conservative consideration, $H_{L}=1.0$ may be considered.

4.3. Predicting the standard deviation of the $F_{R, \text { peak }} s\left(F_{R, \text { standard deviation }}\right)$

Furthermore, the experimental data obtained in the current study shows that $F_{R, \text { standard deviation }} / F_{R, \text { mean }}$ is also a linear function of $j_{s}$, see Figure 37. Linear regression gives the best line to the experimental data:

$$
F_{R, \text { standard deviation }} / F_{R, \text { mean }}=\left(0.088 j_{s}+0.1\right) \pm 0.15
$$

where the variation of \pm 0.15 is the upper/lower bound shown in Figure 37, which was identified by shifting the best fit line up/down to cover all the data points. 


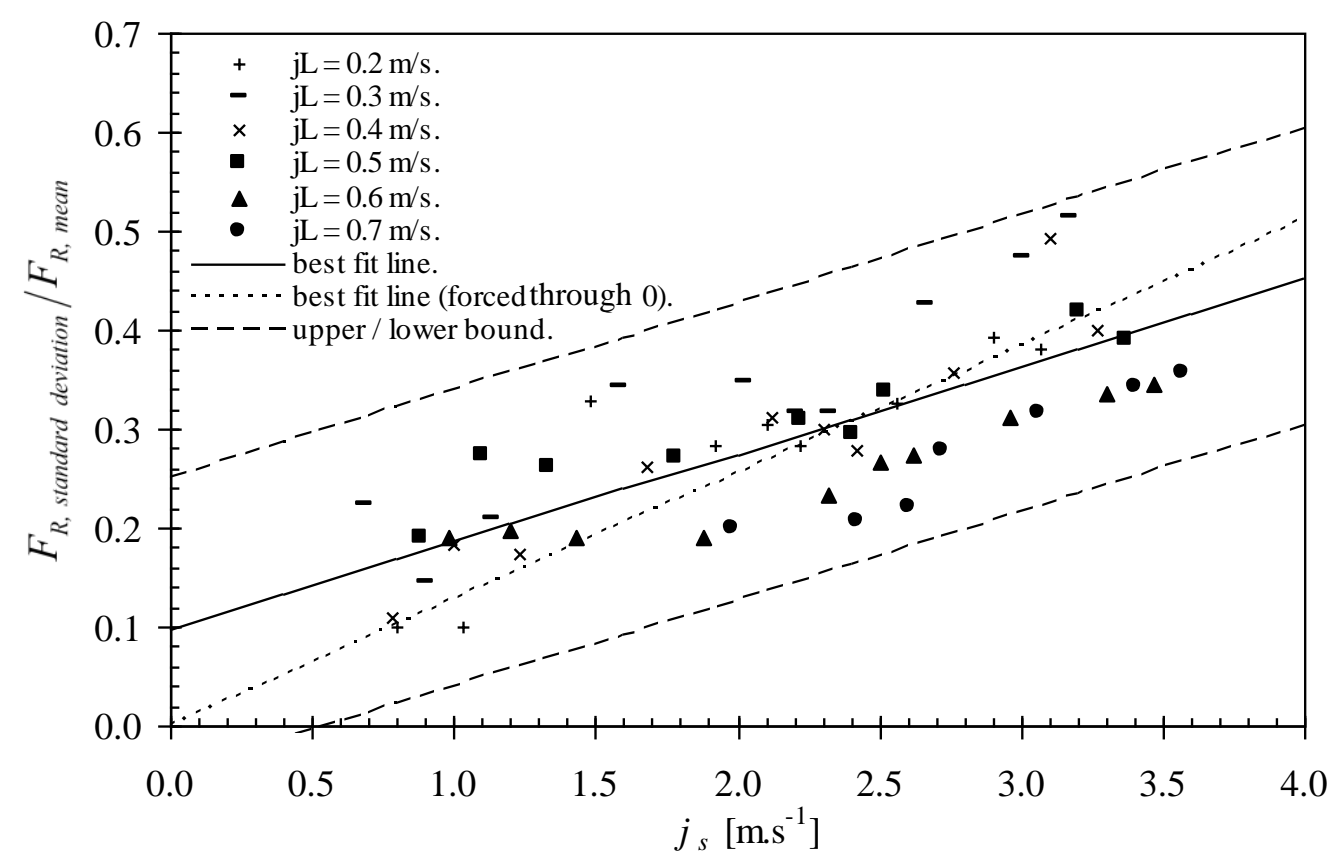

Figure $37 F_{R \text {, standard deviation }} / F_{R, \text { mean }}$ as a function of $j_{s}$.

In Figure 37, a best fit line forced through the origin is shown to check if it is possible to predict $F_{R \text {, standard deviation }} / F_{R \text {, mean }}$ that gives zero value when there is no flow in the pipe. Statistical analysis has been done to check this possibility. In practice, a confidence level of $95 \%$ is customary; therefore, confidence level of $95 \%$ was checked.

In Equation (16), the mean of the intercept at the ordinate was determined as $C=0.1$, which has a standard error, $\sigma_{C}=0.0228$. Details to obtaining $\sigma_{C}$ are given in Appendix. Therefore, forcing the best fit line through the origin is not recommended.

It is shown that the $F_{R, \text { mean } j}$ can be predicted from Equations (13), (14) and (15) using PFM and $F_{R \text {, standard deviation } j}$ for a flow system can be obtained from a relationship as shown in Equation (16). Hence, the distribution of the peak (resultant) forces, $F_{R \text {, peak }}$, acting on 
a pipe bend for an operating condition can be obtained. With this, the fatigue life limit of a pipe bend or pipe fittings in slug flow can be calculated. An example is given in Appendix for estimating the fatigue life of the bend used in the current study, based on statistical data obtained from the experiments.

It is important to emphasize that a representative distribution of forces acting on a pipe bend due to slug (or intermittent) flow, for the range of operating conditions of interest, is needed to predict fatigue life. The current study demonstrates the possibility of predicting fatigue life of a bend based on forces distribution for the flow system and operating conditions described in Section 4.3. For bends in other flow systems, $F_{R \text {, mean } j}$ can be predicted from Equations (13), (14) and (15) using PFM; $F_{R \text {, standard deviation } j}$ can be estimated based on $F_{R \text {, mean } j} \mathrm{~s}$, that are calculated from flow characteristics in each system. There are commercial multiphase flow simulators that simulate transient flow characteristics. These simulators are used to aid the design of flow systems by considering different operating conditions and scenarios over the life of the systems. These simulation results provide transient flow characteristics that can be used to estimate the peak (resultant) forces and the corresponding standard deviation, for fatigue analysis of a bend in a flow system.

\section{Conclusions}

Statistical analysis of the peak (resultant) forces acting on a pipe bend has shown that the repeated forces acting on pipe bends due to slug flow can be described by normal distribution function; square roots of the mean of the peak (resultant) forces, $\sqrt{F_{R, \text { mean }}}$, and the corresponding standard deviations, $\sqrt{F_{R \text {, standarddeviation }}}$, were found to be linear 
functions of flow rates. PFM has been able to predict $\sqrt{F_{R \text {, mean }} / H_{L}} ; F_{R \text {, mean }}$ can be calculated from $H_{L}$ which can be approximated from correlations available in the literature. $\quad F_{R \text {, standard deviation }} / F_{R \text {, mean }}$ was found to be a function of $j_{s}$. Therefore, the probability of the maximum forces (predicted from Piston Flow Model) and 'cumulative damage' can be calculated; this allows prediction of the fatigue life limit of a pipe bend or pipe fittings in slug flow.

\section{Appendix}

\subsection{Metal Fatigue and Example of Fatigue Life Estimation}

Fatigue fractures are due to repeated tensile stresses at levels much below the metal's ultimate tensile strength. They are caused by the simultaneous action of cyclic stresses, tensile stresses, and plastic strain.

A metal's fatigue strength will be less than its yield strength, as determined in a tensile test. In fatigue tests, failure is always a brittle fracture. Because stresses applied are usually less than yield strength, the material, even though it is ductile, has not stretched or otherwise deformed significantly when failure occurs. Fatigue strength is defined as the stress at which failure occurs in a definite number of cycles. Fatigue fracture depends on the number of repetitions in a given range of stresses rather than upon total time under load. Speed has almost no observable effect.

In the case of steels it is found that there is a critical stress called the endurance limit, below which fluctuating stresses cannot cause a fatigue failure; titanium alloys show a 
similar phenomenon (see Figure A.1). No such endurance limit has been found for other non-ferrous metals and other materials.

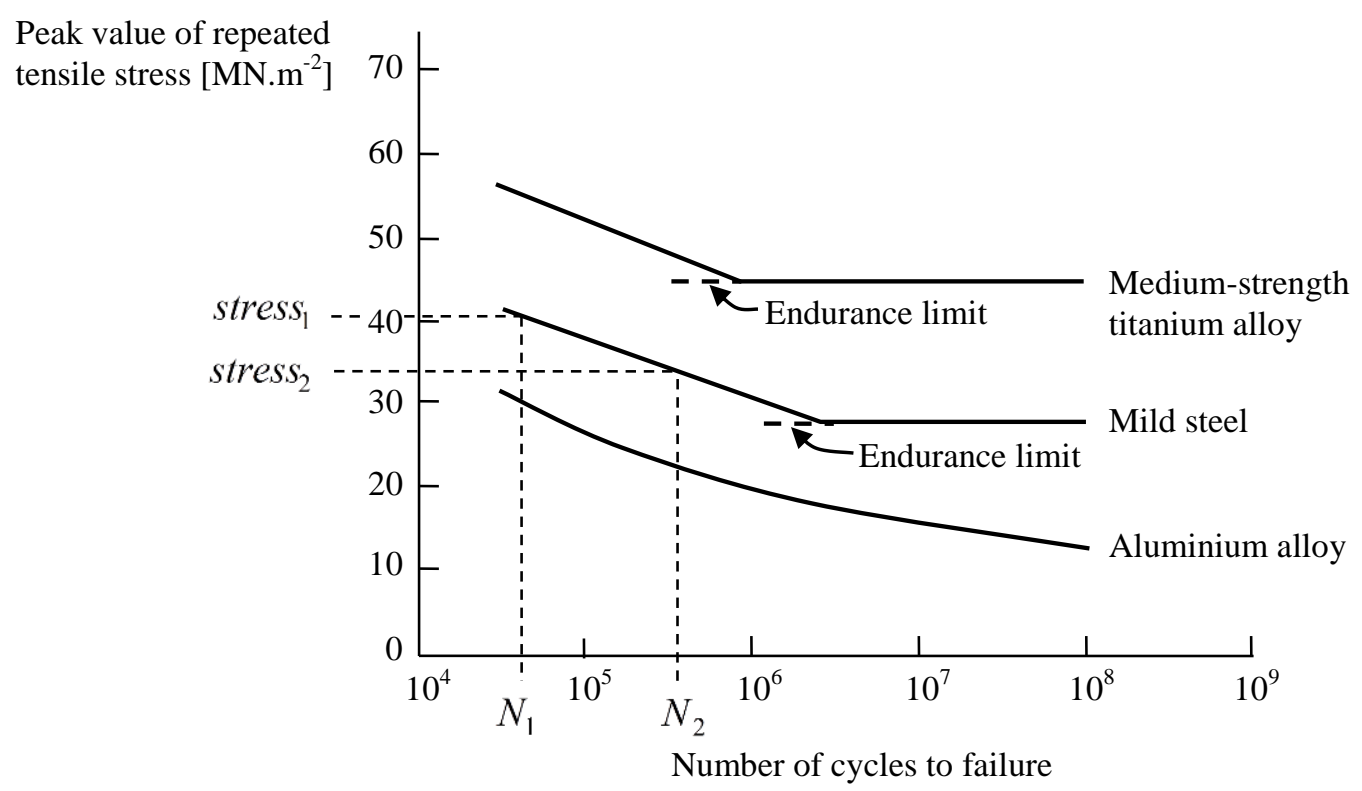

Figure A.1 Fatigue strength ( $S-N$ curve) of various metals under repeated tensile stresses. Source: Case et al. (1999).

Let's assume the bend used in the current study is made of mild steel. Based on the forces distribution obtained from the experiments for the range of $j_{s}$ considered, (tensile) fatigue life of this bend as a result of forces on the bend due to slug flow can be calculated based on wall thickness of the bend, as described below. 
Table A. 1 and Table A. 2 show $F_{R, \text { mean } j}$ and $F_{R \text {, standard deviation } j}$ calculated using Equation (13) and Equation (16) by assuming liquid holdup = 1.0, for the bend with $2 \mathrm{~mm}$ and 0.01 mm wall thicknesses, respectively. In each $F_{R, \text { mean } j}, p_{i}$ for each $F_{R, \text { peak } i}$ can be calculated; $N_{i}$ for each $F_{R, \text { peak } i}$ can be obtained from Figure A.1.

As shown in Figure A.2 for the bend with $2 \mathrm{~mm}$ wall thickness, forces on the bend due to slug flow at the given flowing conditions are far below $F_{\text {endurancelimit }}=6134 N$. Hence, $\sum_{\text {operating condition, } j=1}^{j_{\max }}\left(\sum_{i=1}^{\infty}\left(\frac{N p_{i}}{N_{i}}\right)\right)_{j}=0$ even though the total number of peak force cycles are high (see Table A. 1).

Although it is not a realistic case but for the purpose of illustration, a bend with $0.01 \mathrm{~mm}$ wall thickness is given as an example in Table A. 2. In this case, $F_{\text {endurancelimit }}=30 \mathrm{~N}$. As shown in Figure A.3, $\sum_{\text {operating condition, } j=1}^{j_{\max }}\left(\sum_{i=1}^{\infty}\left(\frac{N p_{i}}{N_{i}}\right)\right)_{j}>0$ for a finite number of peak force cycles depending on the operating conditions and the frequency of forces acting on the bend due to slug flow (see Table A. 2).

This information provides a basis for considering flow system design. An operator can use this information to estimate a conservative value for the remaining life span of a bend based on operational data, if available. 
Table A. 1 Fatigue life estimation for the bend in this study; material = mild steel, wall thickness $=2 \mathrm{~mm}$

\begin{tabular}{|c|c|c|c|c|}
\hline$j_{s}\left[m \cdot s^{-1}\right]$ & $F_{R, \text { mean } j}[N]$ & $\begin{array}{c}F_{R, \text { standard deviation } j}[N] \\
\text { (best fit) }\end{array}$ & $\begin{array}{l}\text { Total number of peak force cycles } \\
\qquad N[-]\end{array}$ & $\sum_{i=1}^{\infty}\left(\frac{N p_{i}}{N_{i}}\right)$ \\
\hline 1.00 & 12 & 2.34 & 1.E+250 & 0.000 \\
\hline 1.20 & 16 & 3.33 & 1. $E+250$ & 0.000 \\
\hline 1.60 & 25 & 6.06 & 1. $E+250$ & 0.000 \\
\hline 2.00 & 36 & 9.97 & 1. $E+250$ & 0.000 \\
\hline 2.40 & 49 & 15.26 & 1. $E+250$ & 0.000 \\
\hline 2.80 & 64 & 22.14 & 1. $E+250$ & 0.000 \\
\hline & & & $\sum_{\text {erating }}^{j_{\max }}\left(\sum_{i=1}^{\infty}\left(\frac{N p_{i}}{N_{i}}\right.\right.$ & 0.000 \\
\hline
\end{tabular}

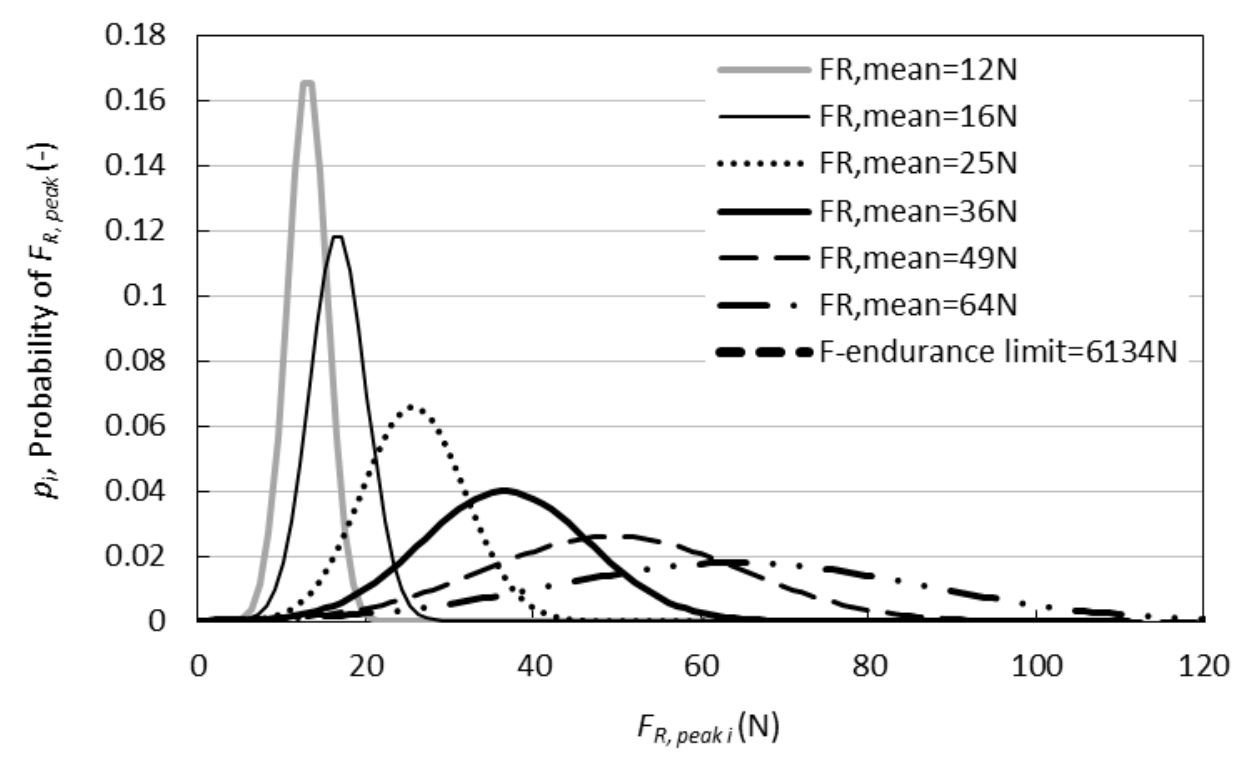

Figure A.2 Distribution of the $F_{R, \text { peak }} \mathrm{s}$ on the bend for $j_{S} \mathrm{~s}$ shown in Table A. 1. $F_{\text {endurancelimit }}=6134 \mathrm{~N}$ for wall thickness of bend $=2 \mathrm{~mm}$. 
Table A. 2 Fatigue life estimation for the bend in this study; material = mild steel, wall thickness $=0.01 \mathrm{~mm}$

\begin{tabular}{|c|c|c|c|c|}
\hline$j_{s}\left[m \cdot s^{-1}\right]$ & $F_{R, \text { mean } j}[N]$ & $\begin{array}{l}F_{R, \text { standard deviation } j}[N] \\
\quad \text { (best fit) }\end{array}$ & $\begin{array}{l}\text { Total number of peak force cycles } \\
\qquad N[-]\end{array}$ & $\sum_{i=1}^{\infty}\left(\frac{N p_{i}}{N_{i}}\right)$ \\
\hline 1.00 & 12 & 2.34 & 1.E+14 & 0.000 \\
\hline 1.20 & 16 & 3.33 & 1. E+09 & 0.005 \\
\hline 1.60 & 25 & 6.06 & 300 & 0.146 \\
\hline 2.00 & 36 & 9.97 & 1 & 0.183 \\
\hline 2.40 & 49 & 15.26 & 1 & 0.603 \\
\hline 2.80 & 64 & 22.14 & 0 & 0.000 \\
\hline & & & $\sum_{\text {erating }}^{j_{\text {max }}}\left(\sum_{i=1}^{\infty}\left(\frac{N p_{i}}{N_{i}}\right)\right.$ & 0.938 \\
\hline
\end{tabular}

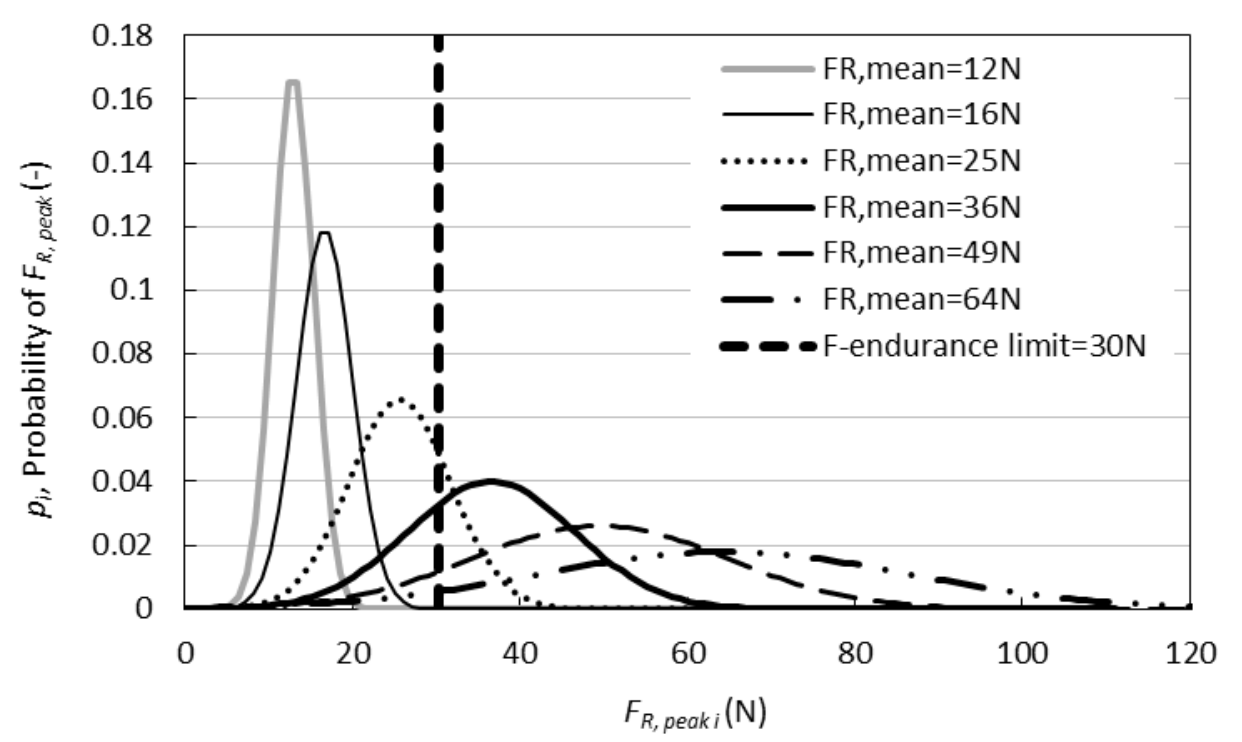

Figure A.3 Distribution of the $F_{R, \text { peak }} \mathrm{s}$ on the bend for $j_{S} \mathrm{~s}$ shown in Table A. 2. $F_{\text {endurancelimit }}=30 \mathrm{~N}$ for wall thickness of bend $=0.01 \mathrm{~mm}$. 
The data plotted in Figure 37 is tabulated as follows:

\begin{tabular}{|c|c|c|c|c|}
\hline No. & $\begin{array}{c}j_{s} \\
{\left[\mathrm{~m} \cdot \mathrm{s}^{-1}\right]}\end{array}$ & $\begin{array}{c}j_{s}^{2} \\
{\left[\mathrm{~m}^{2} \cdot \mathrm{s}^{-2}\right]}\end{array}$ & $\begin{array}{l}Y \\
{[]}\end{array}$ & $\begin{array}{l}Y^{\prime} \\
{[]}\end{array}$ \\
\hline 1 & 0.80 & 0.64 & 0.10 & 0.0047 \\
\hline 2 & 1.03 & 1.06 & 0.10 & 0.0079 \\
\hline 3 & 1.48 & 2.19 & 0.33 & 0.0101 \\
\hline 4 & 1.92 & 3.69 & 0.28 & 0.0003 \\
\hline 5 & 2.10 & 4.41 & 0.30 & 0.0004 \\
\hline 6 & 2.22 & 4.93 & 0.28 & 0.0001 \\
\hline 7 & 2.56 & 6.55 & 0.33 & 0.0000 \\
\hline 8 & 2.90 & 8.41 & 0.39 & 0.0015 \\
\hline 9 & 3.07 & 9.42 & 0.38 & 0.0001 \\
\hline 10 & 0.68 & 0.46 & 0.22 & 0.0044 \\
\hline 11 & 0.90 & 0.81 & 0.15 & 0.0011 \\
\hline 12 & 1.13 & 1.28 & 0.21 & 0.0001 \\
\hline 13 & 1.58 & 2.50 & 0.34 & 0.0111 \\
\hline 14 & 2.02 & 4.08 & 0.35 & 0.0051 \\
\hline 15 & 2.20 & 4.84 & 0.32 & 0.0006 \\
\hline 16 & 2.32 & 5.38 & 0.32 & 0.0002 \\
\hline 17 & 2.66 & 7.08 & 0.43 & 0.0084 \\
\hline 18 & 3.00 & 9.00 & 0.47 & 0.0124 \\
\hline 19 & 3.17 & 10.05 & 0.52 & 0.0187 \\
\hline 20 & 0.78 & 0.61 & 0.11 & 0.0033 \\
\hline 21 & 1.00 & 1.00 & 0.18 & 0.0000 \\
\hline 22 & 1.23 & 1.51 & 0.17 & 0.0012 \\
\hline 23 & 1.68 & 2.82 & 0.26 & 0.0002 \\
\hline 24 & 2.12 & 4.49 & 0.31 & 0.0007 \\
\hline 25 & 2.30 & 5.29 & 0.30 & 0.0000 \\
\hline 26 & 2.42 & 5.86 & 0.28 & 0.0011 \\
\hline 27 & 2.76 & 7.62 & 0.36 & 0.0002 \\
\hline 28 & 3.10 & 9.61 & 0.49 & 0.0147 \\
\hline 29 & 3.27 & 10.69 & 0.40 & 0.0001 \\
\hline 30 & 0.88 & 0.77 & 0.19 & 0.0002 \\
\hline 31 & 1.10 & 1.21 & 0.27 & 0.0062 \\
\hline 32 & 1.33 & 1.77 & 0.26 & 0.0021 \\
\hline 33 & 1.78 & 3.17 & 0.27 & 0.0002 \\
\hline 34 & 2.22 & 4.93 & 0.31 & 0.0002 \\
\hline 35 & 2.40 & 5.76 & 0.29 & 0.0002 \\
\hline 36 & 2.52 & 6.35 & 0.34 & 0.0003 \\
\hline 37 & 3.20 & 10.24 & 0.42 & 0.0015 \\
\hline
\end{tabular}




\begin{tabular}{|lcccc|}
38 & 3.37 & 11.36 & 0.39 & 0.0000 \\
39 & 0.98 & 0.96 & 0.19 & 0.0000 \\
40 & 1.20 & 1.44 & 0.20 & 0.0000 \\
41 & 1.43 & 2.04 & 0.19 & 0.0011 \\
42 & 1.88 & 3.53 & 0.19 & 0.0056 \\
43 & 2.32 & 5.38 & 0.23 & 0.0048 \\
44 & 2.50 & 6.25 & 0.27 & 0.0027 \\
45 & 2.62 & 6.86 & 0.27 & 0.0031 \\
46 & 2.96 & 8.76 & 0.31 & 0.0024 \\
47 & 3.30 & 10.89 & 0.34 & 0.0028 \\
48 & 3.47 & 12.04 & 0.35 & 0.0035 \\
49 & 1.98 & 3.92 & 0.20 & 0.0053 \\
50 & 2.42 & 5.86 & 0.21 & 0.0112 \\
51 & 2.60 & 6.76 & 0.22 & 0.0111 \\
52 & 2.72 & 7.40 & 0.28 & 0.0035 \\
53 & 3.06 & 9.36 & 0.32 & 0.0028 \\
54 & 3.40 & 11.56 & 0.34 & 0.0031 \\
$\mathbf{5 5}$ & 3.57 & 12.74 & 0.36 & 0.0031 \\
\hline$\sum$ & $\mathbf{1 1 9 . 6 1}$ & $\mathbf{2 9 7 . 6 1}$ & & $\mathbf{0 . 1 9}$ \\
\hline
\end{tabular}

$\underline{\text { Notes: }}$

$Y=\sqrt{\frac{F_{R, \text { standard deviation }}}{F_{R, \text { mean experiment }}}}$

$Y^{\prime}=\left(\sqrt{\frac{F_{R, \text { standard deviation }}}{F_{R, \text { mean experiment }}}}-\left(\sqrt{\frac{F_{R, \text { standard deviation }}}{F_{R, \text { mean experiment }}}}\right)_{\text {best fit }}\right)^{2}$

Kirkup (1994) reported that for a best fit line of $Y=M X+C$, the explicit equation to calculate the variance (uncertainty) in $C$ is:

$$
\sigma_{C}=\frac{\sigma_{Y}\left(\sum X_{i}^{2}\right)^{\frac{1}{2}}}{\left[n \sum X_{i}^{2}-\left(\sum X_{i}\right)^{2}\right]^{\frac{1}{2}}}
$$

where $\sigma_{Y}$ is the uncertainty in each $Y$ value of the data point, which was given as: 


$$
\sigma_{Y}=\left[\frac{1}{n-2} \sum\left(Y_{i}-M X_{i}-C\right)^{2}\right]^{\frac{1}{2}}
$$

The reason that $n-2$ appears in the denominator of Equation (A4) equal to the number of degrees of freedom in the calculation; two restrictions are place on the possible values of $Y$ because two quantities are calculated from these values, namely the gradient, $M$, and the intercept, $C$.

From Equation (A4),

$$
\begin{aligned}
\sigma_{Y} & =\left[\frac{1}{n-2} \sum\left(\sqrt{\frac{F_{R, \text { standard deviation }}}{F_{R, \text { mean experiment }}}}-\left(\sqrt{\frac{F_{R, \text { standard deviation }}}{F_{R, \text { mean experiment }}}}\right)_{\text {best fit }}\right)^{2}\right]^{\frac{1}{2}} \\
& =\left[\frac{1}{53}(0.19)\right]^{\frac{1}{2}} \\
& =0.0599
\end{aligned}
$$

Hence,

$$
\begin{aligned}
\sigma_{C} & =\frac{\sigma_{Y}\left(\sum j_{s}^{2}\right)^{\frac{1}{2}}}{\left[n \sum j_{s}^{2}-\left(\sum j_{s}\right)^{2}\right]^{\frac{1}{2}}} \\
& =\frac{0.0599(297.61)^{\frac{1}{2}}}{\left[55(297.61)-(119.61)^{2}\right]^{\frac{1}{2}}} \\
& =0.0228
\end{aligned}
$$




\section{Notation}

$\begin{array}{llc}A & \text { Area } & {\left[\mathrm{m}^{2}\right]} \\ C & \text { Constant } & {[]} \\ D & \text { Pipe diameter } & {[\mathrm{m}]} \\ F & \text { Force } & {[\mathrm{N}]} \\ g & \text { Gravitational acceleration } & {\left[\mathrm{m} . \mathrm{s}^{-2}\right]} \\ h & \text { Liquid height (above pipe base) } & {[\mathrm{m}]}\end{array}$

Hold-up, $H_{k}=\left(A_{k} / A\right)$

$H$

where $k$ is the corresponding fluid phase.

$H_{L} \quad$ Liquid hold-up in the liquid slug body, $H_{L}=\left(A_{L} / A\right)$

ID Internal diameter

$[\mathrm{mm}]$

Superficial velocity (i.e. $Q / A$ )

$\left[\mathrm{m} . \mathrm{s}^{-1}\right]$

$j_{s} \quad$ Superficial slug velocity, $j_{s}=j_{L}+j_{G}$

$\left[\mathrm{m} \cdot \mathrm{s}^{-1}\right]$

$l$

Length

$[\mathrm{m}]$

$l_{e}$

Elongation

[m]

M

Slope of a linear correlation

Number of slugs or force cycles

$N_{i} \quad$ Expected number of cycles to failure at stress $_{i}$ or $F_{i}$

Number of samples

$n_{i}$

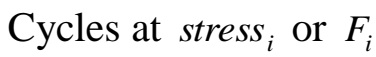

Absolute pressure

Probability 
$u_{s} \quad$ Slug velocity, $u_{s}=1.2 j_{s}+0.41$

$X$

Independent variable in a linear correlation $(Y=M X+C)$

$x-$ direction

$y-\quad y-$ direction

\section{Greek Symbols}

$\alpha$

$\phi$

$\mu$

$\varpi$

$\pi$

$\rho$

$\sigma$

$\sigma_{C}$

$\sigma_{M}$

$\sigma_{Y}$

$\theta$

\section{Subscripts}

See Figure 4: when liquid enters the section, $\mathrm{A}=$ liquid and $\mathrm{B}=$ gas: when A gas enters the section, $\mathrm{A}=$ gas and $\mathrm{B}=$ liquid. $[\mathrm{rad}]$

$[\mathrm{rad}]$

[Pa.s ]

$\left[\operatorname{rad} . \mathrm{s}^{-1}\right]$

[]

$\left[\mathrm{kg} \cdot \mathrm{m}^{-3}\right]$

[N.m ${ }^{-1}$ ]

[]

[]

[]

[ $\mathrm{rad}]$ 
Point $a^{\prime}$ in Figure 4

See Figure 4: when liquid enters the section, $\mathrm{A}=$ liquid and $\mathrm{B}=$ gas: when gas enters the section, $\mathrm{A}=$ gas and $\mathrm{B}=$ liquid.

Point $b^{\prime}$ in Figure 4

Point $c^{\prime}$ in Figure 4

Downstream pipe after the bend

Point $d^{\prime}$ in Figure 4

Point $e^{\prime}$ in Figure 4

Gas phase

Inside pipe (in Equation (2) and Equation (3))

Integer number $i$-th (other than in Equation (2) and Equation (3))

Integer number $j$-th

Superficial velocity

Liquid phase

Length

Slope of a linear correlation, $Y=M X+C$

Maximum

Mean of the peak forces identified from statistical analysis

Outside pipe

The largest force during transit of a slug unit

Piston Flow Model

Resultant 


$\begin{array}{ll}s & \text { Slug unit } \\ u_{s} & \text { Slug velocity } \\ x & x \text {-direction } \\ y & y \text {-direction }\end{array}$

\section{Acknowledgements}

This work has been undertaken within the second stage of the Transient Multiphase Flows Co-ordinated research project. The authors wish to acknowledge the contributions made to this project by the Engineering and Physical Sciences Research Council (EPSRC) and to the following industrial organisations:- ABB; AEA Technology; BG International; BP Amoco Exploration; Chevron; Conoco; Granherne; Institutt for Energiteknikk; Institut Francais du Petrole; Marathon Oil; Mobil North Sea; Norsk Hydro; Scandpower; TotalElfFina. The authors wish to express sincere gratitude for this support. Dr. Tay was funded by Cambridge Commonwealth Trust Bursary and Churchill College Jafar Research Studentship; these financial assistances are also gratefully acknowledged.

\section{References}

Alexander J. M. \& Brewer R. C. (1963). Manufacturing properties of materials, Van Nostrand Reinhold Company.

Case J., Chilver L. \& Ross C. T. F. (1999). Strength of materials and structures, 4th edition, Arnold. 
Cook G. \& Claydon P.W. (1992). Design life prediction of flexible riser systems, MARINFLEX 92 Conference on Flexible Pipes, Umbilicals, Marine Cables.

Fairhurst, C. P. (1983). Two-phase transient phenomena in oil production flowlines, BHRA The Fluid Engineering Centre.

Gatts R. R. (1961). Application of a cumulative damage concept to fatigue, Journal of Basic Engineering, 529-540.

Goodfellow Associates. (1986). Offshore engineering: Development of small oilfields, Graham and Trotman Limited.

Gregory, G. A., Nicholson, M. K., \& Aziz K. (1978). Correlation of the liquid volume fraction in the slug for horizontal gas-liquid slug flow. International Journal of Multiphase Flow, 4, 33-39.

Gurney T. R. (1968). Fatigue of welded structures, Cambridge University Press.

Hargreaves, C. R., \& Slocombe, R. W. (1998). Measurement of the forces on bends in (oil) pipelines due to multiphase flow. Part II Report, 1998/53, University of Cambridge, Department of Chemical Engineering.

Hilsenkopf P. (1988). Experimental study of behaviour and functional capability of ferritic steel elbows and austenitic stainless steel thin-walled elbows, International Journal of Pressure Vessels \& Piping, 33, 111-128.

Kirkup L. (1994). Experimental methods: An introduction to the analysis and presentation of data, John Wiley \& Sons. 
Kitching R. (1979). Limit moment for a smooth pipe bend under in-plane bending, International Journal of Mechanical Science, 21, 731-738.

Klesnil M. \& Lukáš P. (1992). Fatigue of metallic materials, $2^{\text {nd }}$ revised edition, Elsevier.

Malnes D. (1987). Slug flow in vertical, horizontal and inclined pipes, Report IFE/KR/E83/002 V. Institute for Energy Technology, Norway.

Miner M.A. (1945). Cumulative damage in fatigue, Journal of Applied Mechanics, 12, 1945.

Pope J. A. (1959). Metal Fatigue, Chapman \& Hall.

Santana B. W., Fezner D., Edwards N. W. \& Haupt R. W. (1993) Program for improving multiphase slug force resistance at Kuparuk river unit processing facilities, SPE 26104, Richardson, Texas.

Shalaby M. A. \& Younan M. Y. A. (1999). Limit loads for pipe elbows subjected to inplane opening moments and internal pressure, Journal of Pressure Vessel Technology, 121, 17-23.

Shalaby M. A. \& Younan M. Y. A. (1998). Limit loads for pipe elbows with internal pressure under in-plane closing moments, Journal of Pressure Vessel TechnologyTransactions, 120, 35-42.

Tay B.L. \& Thorpe R.B. (2014). Hydrodynamic forces acting on a pipe bends in gasliquid slug flow. Chemical Engineering Research and Design, 92, 812-825. 
Tay B.L. \& Thorpe R.B. (2004). Effects of liquid physical properties on the forces acting on a pipe bend in gas-liquid slug flow. Chemical Engineering Research and Design, 82, 344 - 356.

Tay, B. L., \& Thorpe, R. B. (2002). Forces on pipe bends due to slug flow. The proceeding of $3^{\text {rd }}$ North American Multiphase Technology Conference, Banff, 281300.

Tottle C. R. (1984). An encyclopedia of metallurgy and materials, Macdonald and Evans. 